\title{
Working
}

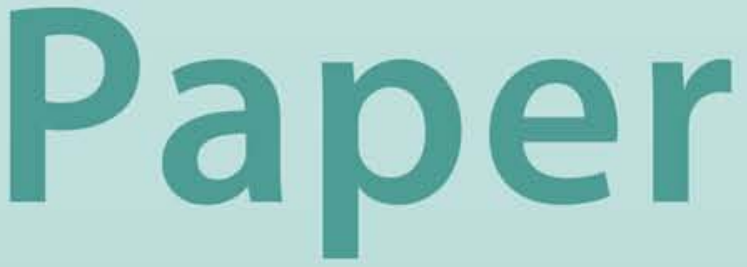


On Brazil's Term Structure: Stylized Facts and Analysis of Macroeconomic Interactions

Luiz Alves, Rodrigo Cabral, Richard Munclinger, and Marco Rodriguez 


\title{
IMF Working Paper
}

Monetary and Capital Markets Department

\section{On Brazil's Term Structure: Stylized Facts and Analysis of Macroeconomic Interactions}

\author{
Prepared by Luiz Alves, Rodrigo Cabral, Richard Munclinger, and Marco Rodriguez ${ }^{12}$ \\ Authorized for distribution by Cheng Hoon Lim
}

May 2011

\begin{abstract}
This Working Paper should not be reported as representing the views of the IMF and the National Treasury of Brazil. The views expressed in this Working Paper are those of the author(s) and do not necessarily represent those of the IMF or IMF policy, nor those of the National Treasury of Brazil. Working Papers describe research in progress by the author(s) and are published to elicit comments and to further debate.
\end{abstract}

This paper characterizes the term structure of Treasury bond yields for Brazil, and estimates a Nelson-Siegel Model to reproduce its stylized facts for the period 2004-2010. For this purpose, this paper uses a software developed by Fund staff. In addition, the paper estimates two versions of the Nelson-Siegel Model that incorporates macroeconomic variables with the aim of assessing the dynamic interactions between the yield curve and the macroeconomy.

JEL Classification Numbers:G12; E43; E44; E58

Keywords: Term structure models of interest rates; interest rates; yields on bonds; Brazil.

Authors’ E-Mail Addresses: luiz.alves@fazenda.gov.br; rodrigo.cabral@fazenda.gov.br; rmunclinger@imf.org; and mrodriguez@imf.org.

\footnotetext{
${ }^{1}$ Luiz Alves and Rodrigo Cabral work for the National Treasury at the Brazilian Ministry of Finance.

${ }^{2}$ The authors would like to thank Ying He for her help with the use of the Macro subroutine of the MCM-TS software, and to William Baghdassarian, Otavio Ladeira de Medeiros, Carlos Medeiros, Tiago Severo, Christopher Towe, and seminar participants at the Brazilian National Treasury for valuable comments.
} 
I. Introduction

II. Methodology and Data....

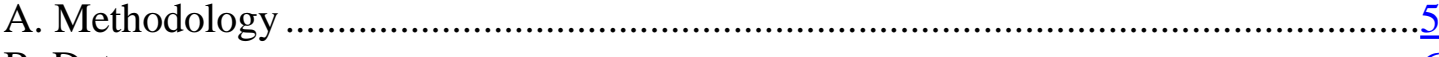

III. The Brazilian Yield Curve ............................................................................................. $\underline{8}$

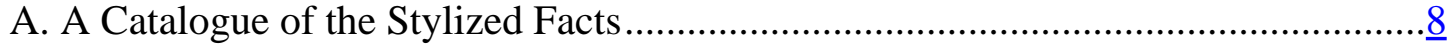

B. A Yield-Only Model for Brazil ...................................................................... 11

C. A Yield-Macro Model for Brazil .................................................................. 115

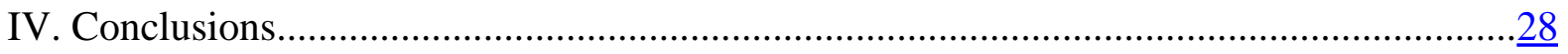

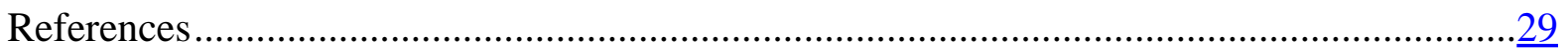

Appendix I. Constructing the Government Zero Coupon Yield Curve Database for Brazil ... $\underline{32}$

Tables

1. General Characteristics of Federal Government Bonds Used for Computing Zero-Coupon

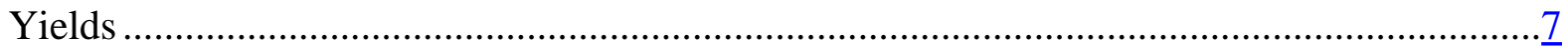

2. Descriptive Statistics, Yield Curves: Jan. 2004-Oct. 2010 .............................................10

3. Descriptive Statistics, Yield Spreads: Jan. 2004-Oct. 2010 ..............................................11

4. Yield-Only Model, Residuals: Jan. 2004-Oct. 2010 .......................................................12

5. Yield-Only Model, Estimated Factors: Jan. 2004-Oct. 2010 ….......................................13

6. Yield-Macro Model I, Estimated Factors: Jan. 2004-Oct. 2010 .........................................16

7. Yield-Macro Model II, Estimated Factors: Jan. 2004-Oct. 2010 .......................................17

8. Yield-Macro Model I, Residuals: Jan. 2004-Oct. 2010 .................................................17

9. Yield-Macro Model II, Residuals: Jan. 2004-Oct. 2010 .................................................17

10. Yield Macro Model, Model I Parameter Estimates (Bootstrapped standard errors in parentheses and t-statistics in brackets) ....................................................................18

11. Yield Macro Model, Model II Parameter Estimates (Bootstrapped standard errors in

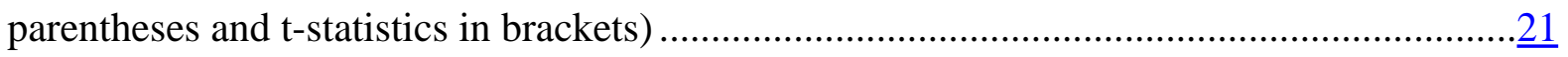

Figures

1. Observed Yield Curves .................................................................................................. 9

2. Observed and Estimated Average Yield Curve ............................................................12

3. Estimates of the Level, Slope, and Curvature in The Yields-Only Model .........................13

4. Model-Based Level, Slope, and Curvature vs. Data-Based Level, Slope, and Curvature...14

5. Model I-Impulse-Response Functions .................................................................23

6. Model II-Impulse-Response Functions................................................................... 


\section{INTRODUCTION}

The yield curve popularly depicts a set of interest rates of bonds of different maturities. More formally, it describes the links among short, medium and long-term nominal bond rates at a given point in time. Such links, however, may change through time, rendering different shapes of the yield curve at different moments and following patters that could be summarized as stylized facts. The goal of this paper is three fold: first, identify and catalogue a set of stylized facts of the yield curve for government bonds during the recent time in Brazil; second, fit a factor model that would capture and explain such facts; and third, explore the linkages between the dynamics of macroeconomic forces and the dynamic evolution of the Brazilian yield curve.

Modeling the stochastic fluctuations in the yield curve over time is commonly used for a variety of purposes. Macroeconomists, debt managers, financial economists and market participants attempt to build and use models of the yield curve that reflect their different motives, e.g., interest rate forecasting or simulation, pricing of fixed-income securities, interest-rate risk management, and market surveillance. In particular, Debt Management Offices (DMOs) around the world have been investing heavily in introducing analytical tools for which modeling and understanding of the dynamics of the yield curve is fundamental. ${ }^{3}$ In addition, in dealing with strategic debt issues, modeling the yield curve allows DMOs to measure the expected cost of alternative debt strategies, i.e., to understand and measure the trade-offs between cost and risk. Also, in trying to determine the optimal composition of the debt, DMOs need models capable of mimicking the different shapes and dynamics of the term structure. ${ }^{4}$

Studies of Brazil's yield curve have mainly focused on forecasting interest rates using limited data sets. A significant body of research on Brazil's yield curve for government securities has made strides into characterizing and understanding its dynamics for the period after the consolidation of the Real Plan in 1994. ${ }^{5}$ However, experiences with domestic and

\footnotetext{
${ }^{3}$ During the last decade, for instance, the Brazilian National Treasury has been developing sophisticated risk management tools, such as the at-risk set of indicators and techniques for determining the composition of optimal portfolios (benchmarks) in an Asset and Liability framework. See Cabral, R., W. Baghdassarian and A. Silva (2006) and National Treasury (2009). Producing these at-risk set of indicators is useful for estimating a cash flow-at-risk or a cost-at-risk measures of the debt, with the aim of capturing the effects of uncertainty.

${ }^{4}$ Brazil recently published its benchmark model (See Cabral et. al (2006)). This model uses correlated stochastic process for interest-rates, real exchange-rates and inflation to bring some macroeconomic consistency to the process of portfolio selection.

${ }^{5}$ See Tabak and Andrade (2001), Valli and Varga (2002), Monteiro (2003), Silveira and Bessada (2003), Lima and Issler (2003), Brito et.al. (2003), Almeida (2004), Almeida, Gomes, Leite and Vicente (2007), Vicente and Tabak (2007), Matsumura and Moreira (2008), Rezende and Ferreira (2008), and Matsumura, Moreira and Vicente (2010).
} 
external macroeconomic volatility left the financial structure for government bonds with high interest rates and very short maturities until about $2002,{ }^{6}$ restricting the amount of information to conduct empirical research on the Brazilian yield curve dynamics. ${ }^{7}$ After 2002, with the consolidation of the main macroeconomic pillars and a good external environment, Brazilian treasury bonds have become more stable and their maturities have lengthened significantly generating the information needed for empirical analysis of yield curve developments. ${ }^{8}$ However, most of this research focused on interest rate description and forecasting, leaving aside considerations of the interactions between financial and macroeconomic variables. More recently, a body of research has emerged that attempt to describe and analyze the joint behavior of the Brazilian yield curve and macroeconomic variables. ${ }^{9}$ However, these studies are still restricted by the limited amount of yield data for medium and long-term maturities. ${ }^{10}$

Most of the previous studies use data on interest rate swaps that are negotiated in the BM\&FBovespa Stock and Futurres Exchange to estimate the zero coupon yields of government bonds. ${ }^{11}$ These swaps, in general, exhibit good liquidity only in the short-term and may convey only limited information about Treasury Bonds’ interest-rate risk. As indicated below, this paper uses zero-coupon yields for government securities that are constructed directly from government securities’ prices and therefore contain unique information about these securities interest-rate risk. Although swap rates may represent a good proxy for the risk-free yield curve, using directly the data from the government bonds could provide a richer set of information. In addition, the paper uses a powerful methodology to extract yield curve factors and for exploring their dynamic interactions with macroeconomic variables.

\footnotetext{
${ }^{6}$ These include events such as electoral volatility in Brazil (2002), the Mexican (1995), Asian (1997), Russian (1998) and Argentinean (2001) crises. Studies that take data since the late1990s could only study the dynamics of a very short-term yield curve.

${ }^{7}$ Nevertheless, some studies, such as Matsumura and Moreira (2008), are able to show that the dynamics of the yield curve in Brazil changed dramatically after 2002.

${ }^{8}$ These events include the change of foreign exchange regime, the introduction of a credible fiscal framework and of an inflation targeting regime.

${ }^{9}$ See Silveira (2005), Matsumara and Moreira (2005), Shousha (2007) and Ribeiro and Pereira (2010).

${ }^{10}$ See the discussion in Section III C below.

${ }^{11}$ The floating rate leg of the swaps is based on the financial deposits (DI) between financial institutions.
} 


\section{Methodology AND DATA}

\section{A. Methodology}

The strategy for modeling the yield curve in this paper assumes that a few latent factors and their associated factor loadings underlie the pricing of tradable bonds. ${ }^{12}$ It expresses a possible large set of yields of various maturities and their evolution through time by the so called Nelson-Siegel model: ${ }^{13}$

$$
y_{t}(\tau)=\beta_{1 t}+\beta_{2 t}\left(\frac{1-e^{-\lambda \tau}}{\lambda \tau}\right)+\beta_{3 t}\left(\frac{1-e^{-\lambda \tau}}{\lambda \tau}-e^{-\lambda \tau}\right),{ }^{14}
$$

where $\beta_{1 t}, \beta_{2 t}, \beta_{3 t}$ and $\lambda$ are parameters, and whose respective loadings are given by 1 , $\left(\frac{1-e^{-\lambda \tau}}{\lambda \tau}\right)$ and $\left(\frac{1-e^{-\lambda \tau}}{\lambda \tau}-e^{-\lambda \tau}\right)$, respectively. The parameter $\lambda$ controls both the exponential decay rate and the maturity at which the loading on $\beta_{3 t}$ reaches its maximum. ${ }^{15}$

The parameters $\beta_{1 t}, \beta_{2 t}$ and $\beta_{3 t}$ in the Nelson-Siegel yield base model (NS model) can be construed as dynamic latent factors. These factors are interpreted as the level, slope and curvature factors, respectively, since their loadings are, respectively, a constant, a decreasing function of $\tau$, and a concave function of $\tau .{ }^{16}$ The time-series statistical properties of the three factors $\beta_{1 t}, \beta_{2 t}$ and $\beta_{3 t}$ underlie the dynamic patterns of the yield curve, and together with

\footnotetext{
${ }^{12}$ This modeling strategy has become very popular among market and central-bank practitioners (Bank of International Settlements, 2005). It was initiated by Nelson and Siegel (1987 and 1988).

${ }^{13} y_{t}(\tau)$ denotes the continuously compounded zero-coupon nominal yield to maturity of a $\tau$-period discount bond.

${ }^{14}$ For estimation purposes, this equation could be expressed as $y_{t}=\Lambda f_{t}+\varepsilon_{t}$, where $y_{t}$ is a vector of observed yields at time $t, f_{t}$ is a vector of factors, $\Lambda$ is the matrix of loadings, and $\varepsilon_{t}$ is a disturbance error.

${ }^{15}$ The estimation approach used here assumes that there is a single constant decay parameter, $\lambda$, for all maturities, $\tau$. This assumption is justified on the grounds of computational tractability; that is, knowing $\lambda$ is sufficient to compute all the other parameters of the model by linear techniques.

${ }^{16} \mathrm{~A}$ heuristic interpretation of the factors along these lines is the following: (i) since yields at all maturities load identically on $\beta_{1 t}$, an increase in $\beta_{1 t}$ increases all yields equally, changing the level of the yield curve; (ii) since short rates load more heavily on $\beta_{2 t}^{\prime}$, an increase in $\beta_{2 t}^{\prime}$ raises short yields more than long yields, thereby changing the slope of the yield curve; and (iii) since short rates and long rates load minimally on $\beta_{3 t}$, an increase in $\beta_{3 t}$ will increase medium-term yields, which load more heavily on it, increasing the yield curve curvature. An additional implication of the NS model is that $y_{t}(0)=\beta_{1 t}+\beta_{2 t}$, i.e., the instantaneous yield depends on both the level and the slope factors.
} 
the parameter $\lambda$, are able to capture a variety of shapes that the yield curve can assume through time. ${ }^{17}$

The NS model can be enhanced to take into account macroeconomic factors. In particular, the NS model can explicitly incorporate macroeconomic factors to analyze the potential bidirectional feedback from the yield curve to the economy and back again. Specifically, the NS model can be extended to study the nature of the links between the factors driving the yield curve and macroeconomic fundamentals. ${ }^{18}$

\section{B. Data}

\section{Yield data}

Yield curves are not observed, and must be estimated from observed bond prices. The empirical analysis in this paper uses monthly estimates of annualized daily compounded zero-coupon Brazilian government bond yields computed by the National Treasury Office of the Ministry of Finance of Brazil. The estimates cover the period between January 2004 and October 2010, i.e., 82 months, and contain 984 monthly observations of yields for 12 maturities: 1, 2, 3, 4, 6, 9, 12, 18, 24, 30, 36, and 48 months.

LTN and NTN-F bonds are used to construct the zero-coupon yields for the 12 maturities (see Table 1). The LTN bonds are pure discount bonds, and, jointly with daily bond price information from ANBIMA, ${ }^{19}$ are used to compute the zero-coupon yields for maturities up to 24 months. ${ }^{20}$ They are also used as the building block for constructing the zero-coupon yields for the larger maturities, from NTN-F bonds, by using interpolation and bootstrapping techniques. ${ }^{21}$

\footnotetext{
${ }^{17}$ The evolution of the yield curve factors is assumed to follow a VAR of order 1, i.e., $\left(f_{t}-\mu\right)=A\left(f_{t-1}-\right.$ $\mu+\eta t$, where $A$, $\mu$, and $\eta t$, are, respectively, a 3x3 matrix of coefficients, a 3x1 vector of means, and a 3x1 disturbance error. See Diebold and Li (2006).

${ }^{18}$ Formally, the vector $f_{t}$, in $y_{t}=\Lambda f_{t}+\varepsilon_{t}$, would include now yield curve factor as well as macroeconomic factors. However, the model assumes that the yields load only on the yield curve factors, $\beta_{1 t}, \beta_{2 t}^{\prime}$ and $\beta_{3 t}$, i.e., the columns in $\Lambda$ multiplying the macro factors are zero. The dynamic interactions between yield curve factors and macroeconomic factors are captured in the expanded VAR in Section III. C. See Diebold, Rudebusch and Auroba (2006).

${ }^{19}$ ANBIMA is the Brazilian Association of Financial and Capital Market Institutions. One of its activities is to provide financial prices needed for the mark-to-market of securities by financial institutions.

${ }^{20}$ While trading in some LTN or NTN-F bonds, specially for medium to large maturities, might not occur in some of the dates for which zero-coupon yield data is reported, synthetic LTN / NTN-F bonds still could be constructed using pricing information on equal maturity instruments reported by ANBIMA.

${ }^{21}$ See Appendix for a detailed description of the procedures used to estimate the zero-coupon yields.
} 


\section{Table 1. General Characteristics of Federal Government Bonds Used for Computing Zero-Coupon Yields $1 /$}

\begin{tabular}{|c|c|c|c|c|c|}
\hline Securities & Description & Coupon & Maximum & Type of Interest & Face Value \\
\hline $\begin{array}{c}\text { LTN } \\
\text { (National Treasury Bills) }\end{array}$ & Short-term, zero-coupon & Zero coupon & $\begin{array}{c}\text { About } \\
24 \text { months } \\
\end{array}$ & & \\
\hline $\begin{array}{c}\text { NTN-F } \\
\text { (National Treasury Notes } \\
- \text { Series F) }\end{array}$ & $\begin{array}{l}\text { Long-term fixed } \\
\text { rate coupon } \\
\text { bonds }\end{array}$ & $\begin{array}{l}10 \text { percent p.a. } \\
\text { paid semiannually }\end{array}$ & $\begin{array}{l}\text { About } \\
10 \text { years }\end{array}$ & Fixed & R. 1,000 \\
\hline
\end{tabular}

Source: National Treasury. Federal Government Bonds: Methodology for Calculating Federal Government Bonds Offered in Primary Auctions.

1/ Recently, the national Treasury extended LTN maturities up to three years.

\section{Macroeconomic data}

Monthly data on a set of macroeconomic variables are used to study the potential bidirectional feedback from the yield curve to the economy and back again. The macroeconomic variables used in this paper can be classified in four groups. The first group consists of four inflation measures; the annual percentage change in the monthly Broad Consumer Price Index (IPCA) ${ }^{22}$, expected inflation and implied inflation extracted from 1-year and 3-year inflation linked bonds. ${ }^{23}$ The second group contains variables that summarize real economic activity, namely, the real economic activity relative to potential and industrial production. ${ }^{24}$ The third group includes variables that capture Brazil's country risk: the Brazilian CDS spread and the level of the Bovespa stock index. ${ }^{25}$ The fourth group includes the interest rate used as target by the Brazilian central bank, i.e., the Selic rate. As in the case of the yields, the data are obtained for the period January 2004 to October 2010.

A Principal Component Analysis (PCA) was used to extract the maximum amount of information from each group of macroeconomic variables. The variables in each of the first three groups were used to extract the respective first principal component associated with each group. That is, we extracted the first principal component from the inflation measures

\footnotetext{
${ }^{22}$ The IPCA is the most important consumer price index, and serves as the reference measure for Brazil's inflation-targeting regime. It is computed by the government statistical institute (IBGE) since 1980, and measures the price change of a consumption basket of households with monthly income between 1 and 40 minimum monthly wages.

${ }^{23}$ Inflation expectations were obtained from the FOCUS report published every Monday by the Central Bank of Brazil. The FOCUS report provides information from the market expectations survey. This survey covers roughly 90 banks and non-financial companies' forecasts for the Brazilian economy.

${ }^{24}$ The Level of Utilization of Manufacturing Installed Capacity, which is the ratio between effective and potential industrial production, is computed using the survey on manufacturing produced by the National Industry Federation (CNI).

${ }^{25}$ The CDS spread that was used originated from Bloomberg (Ticker: BRAZIL CDS USD SR 5Y Corp).
} 
group, the first principal component from the real activity measures group, and the first principal component from the risk perception group. This leaves us with four variables which we call, respectively, "inflation,” “economic activity,” "risk perception” and "policy rate.”26

\section{ThE BRAZILIAN YIELd CURVE}

\section{A. A Catalogue of the Stylized Facts}

(1) Brazilian yields exhibit a sizable amount of inter temporal variation during the period of analysis (see Figure 2 and Table 2). To summarize the yield information at any point in time for the nominal bonds that are traded, we follow the principle that, since only a small number of sources of systematic risk underlie the pricing of financial assets, almost all price information can be extracted with a few constructed factors. ${ }^{27}$ In the context of our modeling approach, we assume that three factors - level, slope and curvature - are enough to summarize the essential features of the term structure at any given point in time, as well as its evolution through time. ${ }^{28}$ Figure 1 and Table 2 show that for the period 2004:1-2010:10 the Brazilian yield curve exhibits sizable inter temporal variation in its level, and, although evident, a much less marked variation in the slope and curvature.

\footnotetext{
${ }^{26}$ The first principal components of the inflation, economic activity and risk perception groups explained, respectively, 87, 79 and 89 percent of the total variation the individual series. The principal components were extracted after all variables were standardized to have zero mean and unit variance.

${ }^{27}$ See Diebold, Piazzesi and Rudebusch (2005) and Litterman and Scheinkman (1991).

${ }^{28}$ In constructing the empirical factors, we define the level as the 4-year yield, the slope as the difference between the 1-month and the 4-year yields, and the curvature as twice the 1-year yield 1minus the sum of the 1-month and 4-year yields. See Diebold and Li (2006).
} 


\section{Figure 1. Observed Yield Curves}

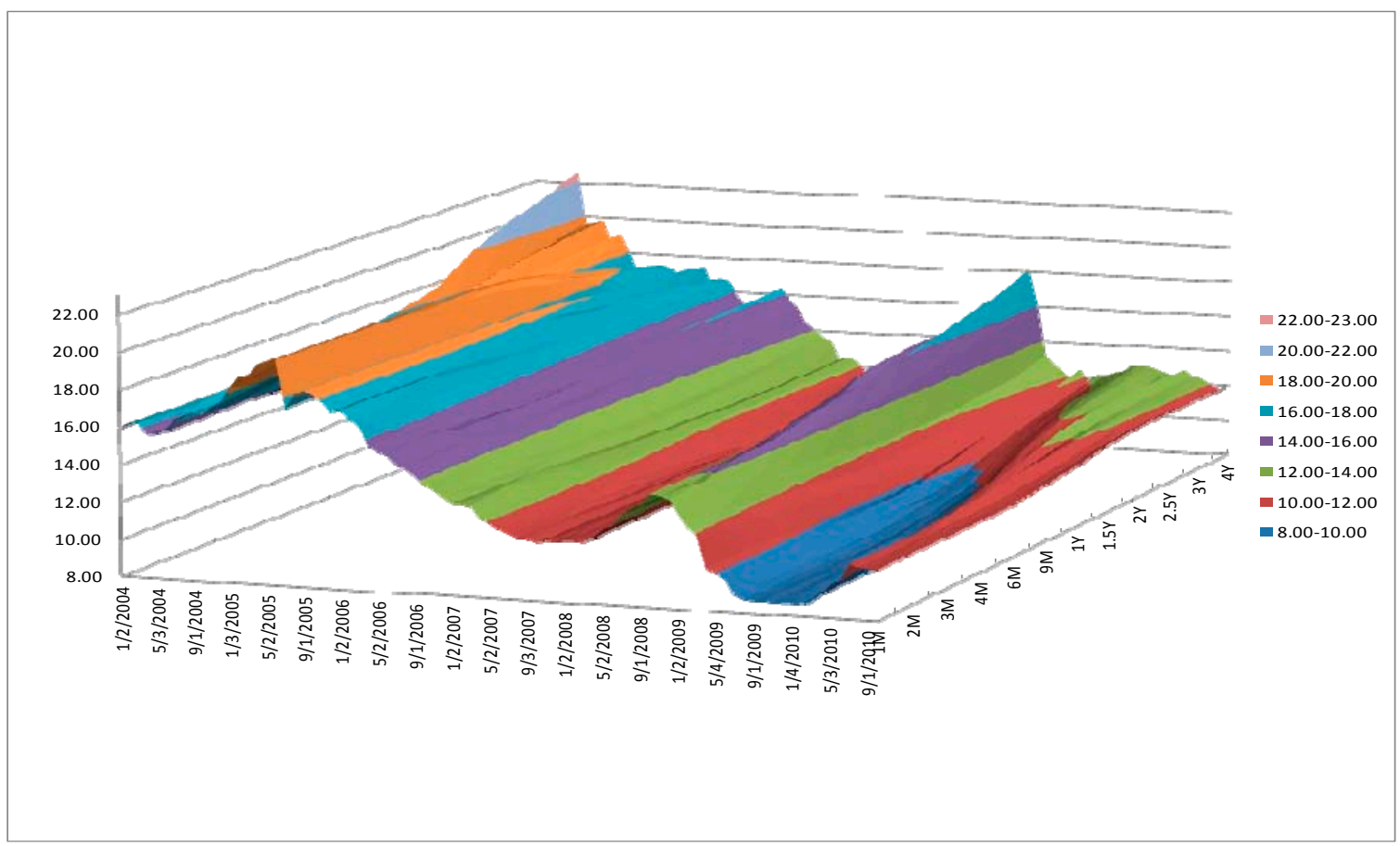

Source: Authors' estimates.

A set of stylized facts characterizing the Brazilian yield curve can be extracted for the period of analysis using an empirical factor approach. Table 2 presents descriptive statistics for the yields at different maturities, and for the yield curve empirical level, slope and curvature factors, while Table 3 displays descriptive statistics for the spreads at different maturities. The last three columns in both Tables show sample autocorrelations at different displacements. Based on these results we can identify the following stylized facts, whose replication should be the test for any potential model of the Brazilian yield curve:

- The average yield curve is upward sloping and concave.

- The yield curve assumes a variety of shapes through time, including upward sloping, downward sloping, humped, and inverted humped. ${ }^{29}$

- Yield dynamics are persistent, while spread dynamics are less persistent. ${ }^{30}$

\footnotetext{
${ }^{29}$ This fact is observed from the range of variation of the empirical slope (-3.146 to 6.650) and curvature (-2.797 to 2.844). In fact the empirical slope was negative in 25 out of the 82 observations, while the empirical curvature was convex in 30 out of the 82 observations.

${ }^{30}$ Persistent yield dynamics are associated with the strong persistence of the level, and less persistent spread dynamics are related to weaker persistence of the slope.
} 
- The short end of the yield curve is more volatile than the long end.

- The level of the yield curve is highly persistent and exhibits high variation relative to its mean in comparison to all the yields and the other empirical factors.

- The slope is less persistent than any single yield but highly variable relative to its mean. ${ }^{31}$

- The curvature is the least persistent of all empirical factors and displays the largest variability relative to its mean.

- While the level is not highly correlated with the slope and curvature, the slope and the curvature show highly negative pairwise correlation. ${ }^{32}$

- The average monthly changes in the yields at all maturities are negative, pointing to an average decline in the yield curve level.

Table 2. Descriptive Statistics, Yield Curves: Jan. 2004-Oct. 2010

\begin{tabular}{lrrrrrrr}
\hline Maturity (Months) & Mean & Std. Dev. & Minimum & Maximum & $\rho(1)$ & $\rho(12)$ & $\rho(24)$ \\
\hline 1 & 13.558 & 3.289 & 8.636 & 19.990 & 0.988 & 0.617 & 0.520 \\
2 & 13.576 & 3.294 & 8.643 & 19.990 & 0.989 & 0.616 & 0.519 \\
3 & 13.593 & 3.287 & 8.657 & 19.991 & 0.988 & 0.606 & 0.512 \\
4 & 13.607 & 3.270 & 8.656 & 19.991 & 0.987 & 0.594 & 0.504 \\
6 & 13.649 & 3.224 & 8.750 & 19.871 & 0.986 & 0.565 & 0.475 \\
9 & 13.741 & 3.137 & 8.945 & 19.806 & 0.983 & 0.528 & 0.432 \\
12 & 13.849 & 3.040 & 9.253 & 19.706 & 0.979 & 0.499 & 0.390 \\
18 & 14.041 & 2.848 & 9.658 & 19.480 & 0.970 & 0.472 & 0.324 \\
24 & 14.202 & 2.738 & 10.334 & 20.006 & 0.960 & 0.506 & 0.317 \\
30 & 14.302 & 2.661 & 10.295 & 21.027 & 0.948 & 0.523 & 0.321 \\
36 & 14.364 & 2.622 & 10.247 & 21.713 & 0.937 & 0.535 & 0.323 \\
48 (level) & 14.446 & 2.607 & 10.144 & 22.576 & 0.922 & 0.526 & 0.312 \\
Slope & 0.888 & 1.991 & -3.146 & 6.650 & 0.849 & 0.099 & 0.225 \\
Curvature & -0.306 & 1.364 & -2.797 & 2.844 & 0.911 & -0.495 & 0.149 \\
\hline
\end{tabular}

Source: Authors' estimates.

\footnotetext{
${ }^{31}$ With an average value of 0.89 , Brazil’s average yield curve during the period of analysis is very flat.

${ }^{32}$ The correlations between the level on one side, and the slope and curvature on the other side are -0.01 and 0.07 , respectively; while the correlation between the slope and the curvature is -0.51 .
} 
Table 3. Descriptive Statistics, Yield Spreads: Jan. 2004-Oct. 2010

\begin{tabular}{lrrrrrrr}
\hline Maturity (Months) & Mean & Std. Dev. & Minimum & Maximum & $\rho(1)$ & $\rho(12)$ & $\rho(30)$ \\
\hline 2 & 0.018 & 0.165 & -0.475 & 0.945 & 0.013 & -0.285 & 0.085 \\
3 & 0.035 & 0.250 & -0.649 & 1.261 & 0.328 & -0.290 & 0.067 \\
4 & 0.050 & 0.317 & -0.741 & 1.420 & 0.586 & -0.302 & 0.069 \\
6 & 0.092 & 0.475 & -1.029 & 1.578 & 0.728 & -0.336 & 0.118 \\
9 & 0.184 & 0.688 & -1.301 & 1.845 & 0.808 & -0.290 & 0.202 \\
12 & 0.291 & 0.870 & -1.503 & 2.153 & 0.832 & -0.218 & 0.284 \\
18 & 0.483 & 1.161 & -1.845 & 2.757 & 0.851 & -0.047 & 0.332 \\
24 & 0.644 & 1.410 & -2.206 & 4.080 & 0.852 & 0.056 & 0.285 \\
30 & 0.744 & 1.626 & -2.415 & 5.101 & 0.845 & 0.079 & 0.261 \\
36 & 0.807 & 1.785 & -2.695 & 5.787 & 0.847 & 0.091 & 0.247 \\
48 & 0.888 & 1.991 & -3.146 & 6.650 & 0.849 & 0.099 & 0.225 \\
\hline
\end{tabular}

Source: Authors' estimates.

\section{B. A Yield-Only Model for Brazil}

The NS model provides a parsimonious framework to accord with the stylized facts of the historical Brazilian yield curve for government securities. In principle, the three-factor framework can accommodate an increasing and concave yield curve, as well as a variety of shapes through time, depending on the values taken by $\beta_{1 t}, \beta_{2 t}$ and $\beta_{3 t}$. Similarly, the high persistence of yield dynamics relative to the small persistence of spread dynamics would correspond to a strong persistence of $\beta_{1 t}$ and a weaker persistence of $\beta_{2 t}$. In addition, the higher volatility of the short end of the curve relative to the long end of the curve would be associated with the positive dependence of the short end on $\beta_{1 t}$ and $\beta_{2 t}$, and of the long end only on $\beta_{1 t}$. Finally, the higher persistence of long rates and the lower persistence of short rates would depend on whether $\beta_{1 t}$ is the most persistent factor.

The three-factor NS model fit well the series of cross sections of Brazilian monthly yields for the period of analysis. Fitting equation (1) to the Brazilian yield data provides estimates of the three factors and the decay parameter in the three-factor NS model $-\beta_{1 t}, \beta_{2 t}, \beta_{3 t}$ and $\lambda .^{33}$ Analysis of the residuals from the estimation procedure, shown in Table 4, indicates that the three-factor NS model provides a good fit to the Brazilian yield curve data. ${ }^{34}$ Using the estimation results, Figure 3 shows that the implied average fitted curve and the average actual yield curve are very close, reinforcing the assessment of the overall good fit provided

\footnotetext{
${ }^{33}$ This paper uses software recently developed by IMF-MCM/TGS to estimate the parameters of NS models. The estimation procedures used in the software are based on the state space methodology. See Gasha et-al (2010).

${ }^{34}$ The residual sample autocorrelations indicate that pricing errors are somewhat persistent, reflecting possible persistent tax and liquidity effects. Also, the estimated means and standard deviations of the residuals, expressed in basis points, show that the mean error is negligible at all maturities.
} 
by the model, and matching some of the stylized facts of the Brazilian yield curve. Table 5 presents descriptive statistics for the estimated factors. From the autocorrelations of the three factors, we can see that the first factor is the most persistence, and that the second factor is more persistent than the third.

Table 4. Yield-Only Model, Residuals: Jan. 2004-Oct. 2010

\begin{tabular}{lrrrrrrr}
\hline Maturity (Months) & Mean & Std. Dev. & Minimum & Maximum & $\rho(1)$ & $\rho(6)$ & $\rho(12)$ \\
\hline 1 & 0.014 & 0.182 & -0.981 & 0.445 & 0.323 & 0.173 & -0.332 \\
2 & 0.010 & 0.046 & -0.108 & 0.124 & 0.163 & 0.090 & -0.332 \\
3 & 0.003 & 0.058 & -0.164 & 0.224 & 0.047 & 0.123 & -0.320 \\
4 & -0.009 & 0.073 & -0.188 & 0.309 & 0.592 & 0.103 & -0.279 \\
6 & -0.023 & 0.085 & -0.260 & 0.255 & 0.751 & 0.074 & -0.392 \\
9 & -0.020 & 0.050 & -0.127 & 0.092 & 0.698 & 0.187 & -0.299 \\
12 & -0.001 & 0.028 & -0.110 & 0.059 & 0.507 & -0.057 & -0.098 \\
18 & 0.025 & 0.144 & -0.592 & 0.313 & 0.720 & 0.156 & -0.284 \\
24 & 0.044 & 0.118 & -0.297 & 0.477 & 0.564 & 0.040 & -0.231 \\
30 & 0.029 & 0.066 & -0.143 & 0.289 & 0.408 & -0.073 & -0.137 \\
36 & -0.002 & 0.020 & -0.068 & 0.075 & 0.585 & 0.093 & -0.353 \\
48 & -0.055 & 0.133 & -0.376 & 0.296 & 0.658 & -0.064 & -0.301 \\
\hline
\end{tabular}

Source: Authors' estimates.

Figure 2. Observed and Estimated Average Yield Curve

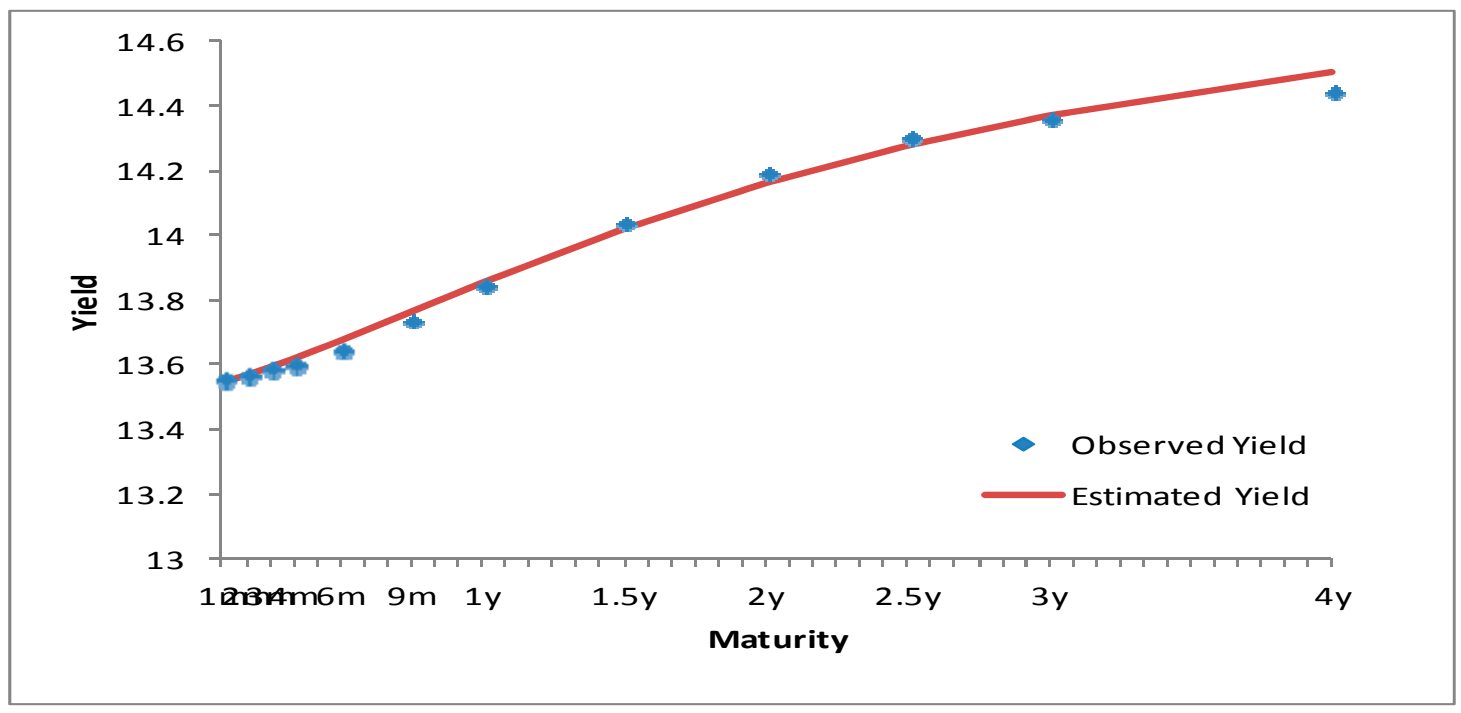

Source: Authors' estimates. 
Table 5. Yield-Only Model, Estimated Factors: Jan. 2004-Oct. 2010

\begin{tabular}{lrrrrrrr}
\hline Factor & Mean & Std. Dev. & Minimum & Maximum & $\rho(1)$ & $\rho(3)$ & $\rho(6)$ \\
\hline & 14.965 & 2.819 & 9.639 & 26.064 & 0.860 & 0.639 & 0.411 \\
$\hat{\beta}_{1}$ & 1.440 & 3.139 & -5.347 & 9.128 & 0.873 & 0.651 & 0.354 \\
$\hat{\beta}_{3}$ & -1.138 & 4.331 & -10.031 & 8.787 & 0.906 & 0.629 & 0.089 \\
$\hat{\beta}_{3}$ & & & & & & &
\end{tabular}

Source: Authors' estimates.

The evolution of the estimated factors, $\left\{\hat{\beta}_{1 t}, \hat{\beta}_{2 t}, \hat{\beta}_{3 t}\right\}$, characterizes the yield curve dynamics and reproduces several stylized facts of the Brazilian yield curve. Table 5 presents descriptive statistics for the estimated factors. From the autocorrelations of the three factors, we can see that the first factor, which is positive and fluctuates around 15 percent, is the most persisten and less volatile; and that the second factor, positive and averaging around 1.4, is more persistent and less volatile than the third, while taking negative and positive values. ${ }^{35}$ Figure 4 displays the three estimated factors of the model for comparative assessment, and Figure 5 plots each of the factors together with their respective empirical proxies. The plots in Figure 5 corroborate the claim that the three factors of the model match up the level, slope and curvature. The correlations between the estimated factors and their empirical proxies are $\rho\left(\hat{\beta}_{1 t}, l_{t}\right)=0.89, \rho\left(\hat{\beta}_{2 t}, s_{t}\right)=0.98$, and $\rho\left(\hat{\beta}_{3 t}, c_{t}\right)=0.99$, where $\left\{l_{t}, s_{t}, c_{t}\right\}$ stands, respectively, for the empirical level, slope and curvature of the yield curve, as defined above. In sum, the level, slope, and curvature factors provide a good representation of the yield curve.

Figure 3. Estimates of the Level, Slope, and Curvature in the YieldsOnly Model

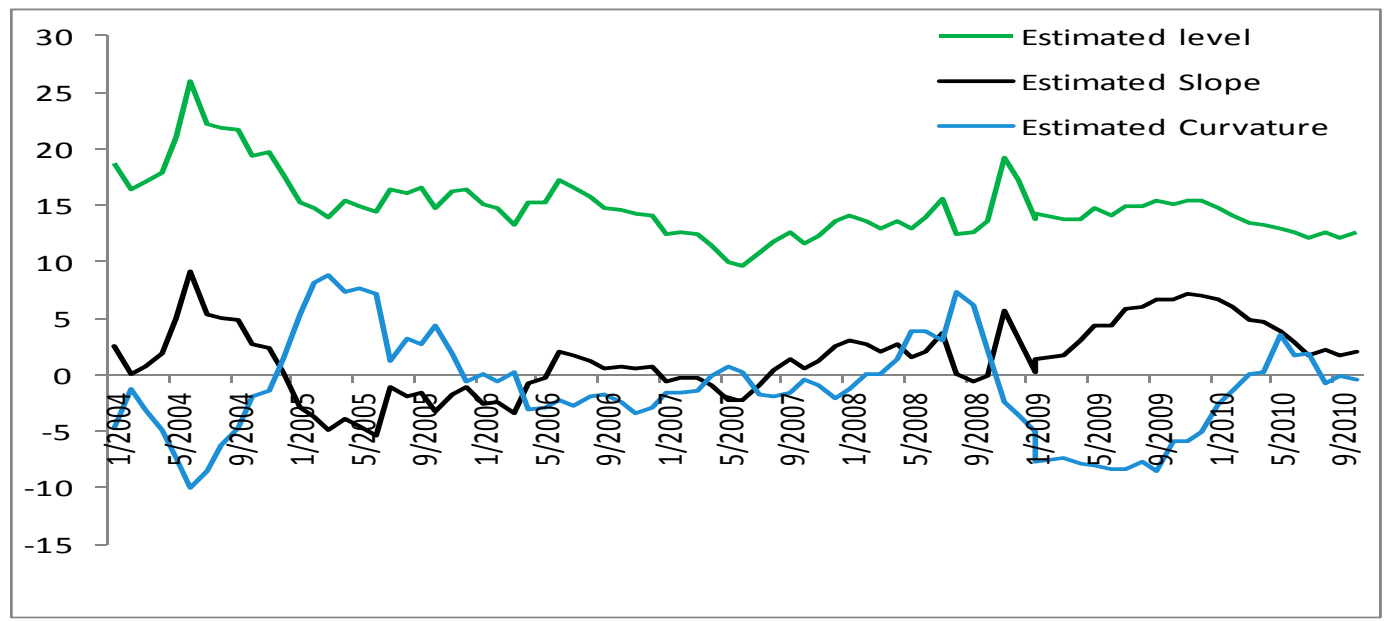

Source: Authors' estimates.

\footnotetext{
${ }^{35}$ Since the long rates load heavily on the level factor, this result matches the fact that the long end of the curve is more persistent than the short end of the curve. On the other hand, since the short end of the curve loads on both the level and the slope they are more volatile than the long end of the curve.
} 
Figure 4. Model-Based Level, Slope, and Curvature vs.

Data-Based Level, Slope, and Curvature
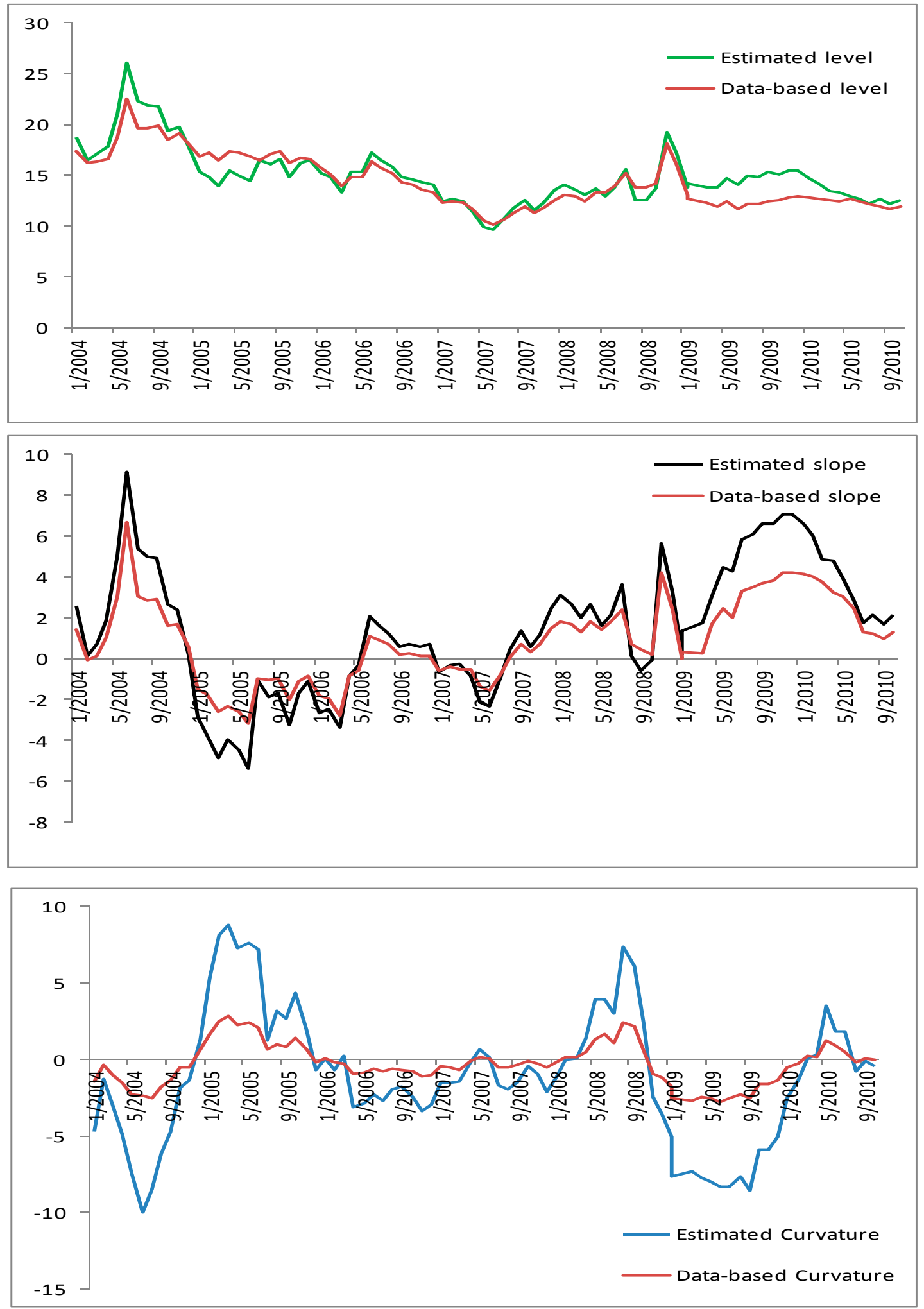

Source: Authors' estimates. 


\section{A Yield-Macro Model for Brazil}

An economically meaningful analysis of yield factor dynamics would require a framework that relates them to macroeconomic fundamentals. As noticed earlier, the NS model provides a framework that allows for a straightforward inclusion of macroeconomic factors, supplying the basis for analysis and assessment of the dynamic interactions between the economy and the yield curve. In this section we aim to characterize the links between $\hat{\beta}_{1 t}, \hat{\beta}_{2 t}, \hat{\beta}_{3 t}$ and a set of variables that would capture the macroeconomic dynamics in Brazil. We present results from two models, one including the three yield factors, the inflation variable, the economic activity variable and the policy rate variable (Model I); and the other replacing the policy rate variable for the risk perception variable (Model II). ${ }^{36}$

The econometric results from the estimation of the parameters in the transition equation are severely affected by insurmountable data restrictions. Each estimated yield-macro model to be estimated consists of three term structure factors and three macroeconomic factors. ${ }^{37}$ This implies that, while 63 parameters are estimated in the transition equation, only 492 data points are available, ${ }^{38}$ or, what amounts the same, only 82 data points are used to estimate 7 coefficients in each equation of the VAR system. ${ }^{39}$ As a result, the asymptotic standard errors reported from OLS estimation of the transition equation are unreliable and inference based on them may be misleading. In addition, computation of the standard errors for the VAR coefficients and the impulse response functions forthcoming from the VAR did not capture the sample variation in the term structure factors that originates in the measurement

\footnotetext{
${ }^{36}$ Recent research has found that shocks to country spreads are important in explaining an important part of the business cycle in Emerging Market Economies (EME). Periods of low interest rates are typically associated with economic expansions and times of high interest rates are often characterized by depressed levels of aggregate activity. For instance, the estimated correlations for a group of EME are: Argentina 0.67, Brazil 0.51, Ecuador 0.80, Mexico 0.58, Peru 0.37, the Philippines 0.02, South Africa 0.07. See Uribe and Yue (2006).

${ }^{37}$ This number of variables is widely viewed to be the minimum set of macroeconomic factors necessary to capture basic macroeconomic dynamics. See Rudebusch and Svensson (1999).

${ }^{38}$ The total number of parameters to be estimated consists of 7 coefficients for the each equation in the system (42 in total), together with 21 covariances in the variance-covariance matrix of errors.

${ }^{39}$ The problem originates not with the macroeconomic variables, for which monthly data are available for a substantial amount of years before 2004, but with the yield data available for estimating the yield factors. For years before 1994, Brazil experienced acute macroeconomic instability, marked by high and variable inflation rates and low and volatile economic growth, which led to a financial structure for government bonds characterized by high interest rates and very short maturities. Furthermore, as noted above, until 2002 Brazil was affected by a series of international crises in other emerging market economies. As a consequence, only until recently, after the consolidation of the pillars of macroeconomic stability were introduced and cemented into agents' expectations, are sufficient maturities available in the government bonds to estimate term structure dynamics reliably.
} 
equation. ${ }^{40}$ To improve the reliability of standard errors and impulse response bounds, we made use of bootstrapping techniques. ${ }^{41}$

Both yield-macro models provide good fitting of the yield curve and their estimates of the yield factors model are very similar to those obtained in the yield-only model. ${ }^{42}$ Tables 6 and 7 show the descriptive statistics of the estimated factors in the yield-macro model, whose values and statistical properties are identical, and also very similar to those of the yield-only model presented in Table 5. In addition, Tables 8 and 9 display the means and standard deviations of the measurements errors from the yield-macro models, which are also very close, and similar to those of the yield-only model shown in Table 4. Specifically, the mean errors and the standard deviations are very small, suggesting a very good fit of the yieldmacro models to the Brazilian Treasury yield data. ${ }^{43}$

Table 6. Yield-Macro Model I, Estimated Factors: Jan. 2004-Oct. 2010

\begin{tabular}{lrrrrrrr}
\hline Factor & Mean & Std. Dev. & Minimum & Maximum & $\rho(1)$ & $\rho(3)$ & $\rho(6)$ \\
\hline & & & & & & & \\
$\hat{\beta}_{4}$ & 14.965 & 2.819 & 9.647 & 26.045 & 0.860 & 0.638 & 0.411 \\
$\hat{\beta}_{3}$ & 1.441 & 3.140 & -5.352 & 9.121 & 0.873 & 0.651 & 0.354 \\
$\hat{\beta}_{3}$ & -1.137 & 4.331 & -9.957 & 8.797 & 0.906 & 0.629 & 0.090 \\
\hline
\end{tabular}

Source: Authors' estimates.

\footnotetext{
${ }^{40}$ We experimented with several econometric strategies to reduce the severity of the data limitations. These included; (i) reducing the size of the system by focusing on only two yield factors and three macroeconomic variables, (ii) imposing restrictions on the VAR system, and (iii) moving from monthly to weekly frequency. These strategies introduced other problems in estimation and were not, in our view, superior to the models estimated in the paper. In particular, reducing the number of factors resulted in a very high correlation between level and slope factors. The restricted VAR did not pass the stability test as more than one eigenvalue of the transition matrix was greater than one. Using weekly data introduced difficulties associated with high frequency data, such as highly persistent errors in the transition and measurement equations.

${ }^{41}$ The bootstrapping algorithm is a non-parametric Monte Carlos bootstrap, which focused on the maximum likelihood estimate (MLE). This algorithm was specifically tailored for state space models and involves obtaining new data samples via sampling from standard errors of the model at the MLEs. The standard errors of the parameters and the bounds for the impulse response function were wider as a result, but they are more liable since the small sample bias was removed. See Stoffer and Wall (1991).

${ }^{42}$ The MCM Term Structure Software includes an additional subroutine that extends the econometric procedures used to estimate the yield-only model to estimate the yield factors of a model that include macroeconomic variables.

${ }^{43} \mathrm{As}$ in the yield-only model, the estimated means and standard deviations of the residuals, expressed in basis points, show that the mean error is negligible at all maturities.
} 
Table 7. Yield-Macro Model II, Estimated Factors: Jan. 2004-Oct. 2010

\begin{tabular}{lrrrrrrr}
\hline Factor & Mean & Std. Dev. & Minimum & Maximum & $\rho(1)$ & $\rho(3)$ & $\rho(6)$ \\
\hline$\hat{\beta}_{1}$ & 14.965 & 2.819 & 9.647 & 26.045 & 0.860 & 0.638 & 0.411 \\
$\hat{B}_{3}$ & 1.441 & 3.140 & -5.352 & 9.121 & 0.873 & 0.651 & 0.354 \\
$\hat{\beta}_{3}$ & -1.137 & 4.331 & -9.957 & 8.797 & 0.906 & 0.629 & 0.090 \\
\hline
\end{tabular}

Source: Authors' estimates.

Table 8. Yield-Macro Model I, Residuals: Jan. 2004-Oct. 2010

\begin{tabular}{lrrrrrrr}
\hline Maturity (Months) & Mean & Std. Dev. & Minimum & Maximum & $\rho(1)$ & $\rho(6)$ & $\rho(12)$ \\
\hline 1 & 0.014 & 0.181 & -0.973 & 0.448 & 0.325 & 0.174 & -0.332 \\
2 & 0.010 & 0.047 & -0.116 & 0.125 & 0.158 & 0.084 & -0.332 \\
3 & 0.003 & 0.058 & -0.164 & 0.227 & 0.046 & 0.123 & -0.320 \\
4 & -0.009 & 0.073 & -0.186 & 0.310 & 0.592 & 0.106 & -0.279 \\
6 & -0.023 & 0.085 & -0.261 & 0.254 & 0.751 & 0.075 & -0.392 \\
9 & -0.020 & 0.050 & -0.130 & 0.093 & 0.698 & 0.177 & -0.299 \\
12 & -0.001 & 0.029 & -0.114 & 0.060 & 0.502 & -0.067 & -0.098 \\
18 & 0.025 & 0.144 & -0.595 & 0.313 & 0.719 & 0.154 & -0.284 \\
24 & 0.044 & 0.117 & -0.292 & 0.475 & 0.564 & 0.043 & -0.231 \\
30 & 0.029 & 0.066 & -0.143 & 0.289 & 0.409 & -0.074 & -0.137 \\
36 & -0.002 & 0.020 & -0.068 & 0.079 & 0.583 & 0.084 & -0.353 \\
48 & -0.055 & 0.132 & -0.377 & 0.283 & 0.656 & -0.059 & -0.301 \\
\hline
\end{tabular}

Source: Authors' estimates.

Table 9. Yield-Macro Model II, Residuals: Jan. 2004-Oct. 2010

\begin{tabular}{lrrrrrrr}
\hline Maturity (Months) & Mean & Std. Dev. & Minimum & Maximum & $\rho(1)$ & $\rho(6)$ & $\rho(12)$ \\
\hline 1 & 0.014 & 0.182 & -0.981 & 0.445 & 0.323 & 0.173 & -0.332 \\
2 & 0.010 & 0.046 & -0.108 & 0.124 & 0.163 & 0.090 & -0.332 \\
3 & 0.003 & 0.058 & -0.164 & 0.224 & 0.047 & 0.123 & -0.320 \\
4 & -0.009 & 0.073 & -0.188 & 0.309 & 0.592 & 0.103 & -0.279 \\
6 & -0.023 & 0.085 & -0.260 & 0.255 & 0.751 & 0.074 & -0.392 \\
9 & -0.020 & 0.050 & -0.127 & 0.092 & 0.698 & 0.187 & -0.299 \\
12 & -0.001 & 0.028 & -0.110 & 0.059 & 0.507 & -0.057 & -0.098 \\
18 & 0.025 & 0.144 & -0.592 & 0.313 & 0.720 & 0.156 & -0.284 \\
24 & 0.044 & 0.118 & -0.297 & 0.477 & 0.564 & 0.040 & -0.231 \\
30 & 0.029 & 0.066 & -0.143 & 0.289 & 0.408 & -0.073 & -0.137 \\
36 & -0.002 & 0.020 & -0.068 & 0.075 & 0.585 & 0.093 & -0.353 \\
48 & -0.055 & 0.133 & -0.376 & 0.296 & 0.658 & -0.064 & -0.301 \\
\hline
\end{tabular}

Source: Authors' estimates. 
The yield-macro models are able to capture the degree and the nature of the dynamic interactions between the economy and the yield curve. Tables 10 and 11 present the estimates of the parameters of the two yield-macro models containing, respectively, the key macroeconomic and yield curve interactions. To guide our interpretations of the results, we use the partitioning of matrix A given by

$$
\text { (2) } \mathrm{A}=\left(\begin{array}{ll}
A_{1} & A_{2} \\
A_{3} & A_{4}
\end{array}\right)
$$

where $A_{1}$ contains the coefficients showing the influence of lagged yield curve factors on current yield curve factors, $A_{3}$ the coefficients showing the lagged influence of yield curve factors on current macroeconomic factors, $A_{2}$ the coefficients showing the influence of lagged macroeconomic factors on current yield curve factors, and $A_{4}$ the coefficients showing the influence of lagged macroeconomic factors on current macroeconomic factors.

\section{Table 10. Yield Macro Model, Model I Parameter Estimates (Bootstrapped standard errors in parentheses and t-statistics in brackets)}

\begin{tabular}{|c|c|c|c|c|c|c|}
\hline & Level(-1) & Slope(-1) & Curvature(-1) & $\operatorname{INF}(-1)$ & $\mathrm{EA}(-1)$ & $R(-1)$ \\
\hline \multirow[t]{3}{*}{ Level } & 0.43 & -0.05 & -0.25 & 0.36 & 0.30 & 0.17 \\
\hline & (0.40982) & $(0.37875)$ & $(0.09407)$ & $(0.11937)$ & $(0.21335)$ & $(0.38329)$ \\
\hline & [1.03814] & {$[-0.12080]$} & {$[-2.62080]$} & [2.98915] & [1.39421] & [0.44211] \\
\hline \multirow[t]{3}{*}{ Slope } & -0.17 & 0.52 & -0.26 & 0.26 & 0.23 & -0.19 \\
\hline & $(0.43228)$ & $(0.39730)$ & $(0.09906)$ & $(0.12692)$ & $(0.22493)$ & $(0.40176)$ \\
\hline & {$[-0.39061]$} & [1.31993] & [-2.66979] & [2.02725] & [1.02344] & {$[-0.47910]$} \\
\hline \multirow[t]{3}{*}{ Curvature } & -0.81 & 0.93 & 0.89 & 0.13 & 0.13 & 0.81 \\
\hline & $(0.56234)$ & $(0.52177)$ & $(0.12984)$ & $(0.17326)$ & $(0.30199)$ & $(0.52624)$ \\
\hline & [-1.43499] & [1.78638] & [6.82368] & [0.75249] & [0.43382] & [1.53666] \\
\hline \multirow[t]{3}{*}{ INF } & 0.02 & -0.05 & -0.06 & 0.94 & 0.20 & -0.03 \\
\hline & $(0.28599)$ & $(0.26526)$ & $(0.06425)$ & $(0.08749)$ & $(0.15216)$ & $(0.27232)$ \\
\hline & {$[0.07946]$} & {$[-0.17357]$} & {$[-0.91372]$} & [10.77517] & [1.31176] & {$[-0.09520]$} \\
\hline \multirow[t]{3}{*}{ EA } & -0.23 & 0.16 & -0.05 & 0.05 & 0.90 & 0.16 \\
\hline & (0.17815) & $(0.16625)$ & $(0.04157)$ & $(0.05400)$ & (0.09918) & $(0.17021)$ \\
\hline & {$[-1.30490]$} & [0.94014] & {$[-1.23331]$} & [0.96456] & [9.02858] & [0.92960] \\
\hline \multirow[t]{3}{*}{ TR } & 0.20 & -0.14 & 0.07 & 0.06 & 0.08 & 0.77 \\
\hline & $(0.10247)$ & $(0.09397)$ & $(0.02334)$ & $(0.02921)$ & $(0.05229)$ & $(0.09451)$ \\
\hline & [1.94267] & {$[-1.53993]$} & [3.05086] & [2.16653] & [1.61759] & [8.19213] \\
\hline
\end{tabular}

Source: Authors' estimates. 


\section{Model I}

- For Model I, a total of 11 coefficients are significant, 4 diagonal and 7 off-diagonal. In particular, all the diagonal coefficients of $A_{4}$ are significant, while in $A_{1}$ only the diagonal curvature is significant. An additional result from the estimated diagonal coefficients is that macroeconomic factors are more persistent than yield curve factors, with the exception of the curvature, whose persistence is higher than that of the policy rate. Also, in $A_{3}$, the level and the curvature significantly affect positively the target rate; while, in $A_{2}$, the inflation rate significantly affects positively the level and the slope of the yield curve. Finally, in $A_{1}$, the curvature affects negatively the level and the slope, while, in $A_{4}$, inflation significantly affects positively the target rate. A key result from Model I, thus, is that the policy rate in Brazil, for the period under analysis, has been informed both by financial factors, i.e., the level and curvature, ${ }^{44}$ and by macroeconomic factors, namely, the inflation rate and its own lagged value, but failed to have a significant influence on next period's inflation and economic activity. ${ }^{45}$

\section{Model II}

- For Model II, a total of 14 coefficients are significant, including all 6 diagonal elements and 8 off-diagonal elements. A closer look at the diagonal coefficients shows that, as in Model I, macroeconomic factors are more persistent than yield curve factors. ${ }^{46}$ In addition, the estimates for $A_{3}$ show that no lagged yield factor affects significantly any current macro factor; while, in $A_{2}$, the inflation rate has a positive and significant effect on the curvature of the yield curve, i.e., an increase in inflation will increase the next period yields in the mid section of the yield curve, economic activity significantly affects positively both the level and the slope of the

\footnotetext{
${ }^{44}$ There are two interpretations of this link: Either the central bank may be reacting to yields in setting the target rate, or the yields are reacting to macroeconomic information in anticipation of the central bank decisions. This last possibility occurs when the central bank has been able to set up a predictable policy reaction to macroeconomic information.

${ }^{45}$ Assuming that yields anticipates central bank decisions regarding the target rate, the influence of monetary policy on inflation and economic activity might occur indirectly through the effects of yield curve factors on the macroeconomic variables. However, in order to have a more deep understanding of such relations, it would be needed a VAR of order higher than 1, but the present database provides limited degree of freedom to do that. For the sake of illustration, when modeling interactions between yield curve and macro factors, Rudebusch and Wu (2008) change their model's equations to include more lags when dealing with monthly data compared to lower frequency data.

${ }^{46}$ Although the value of the diagonal coefficient of risk aversion is greater than 1 , stationarity of the VAR is assured since all of its eigenvalues are less than 1.
} 
yield curve, i.e., an increase in economic activity will raise the next period's level and slope, while risk perception affects significantly all the factors in the yield curve. Specifically, for the latter effect, and for the period of analysis, an increase in risk aversion would increase more than proportionally the next period level and the slope of the yield curve, and strongly reduces its curvature. ${ }^{47}$ In $A_{1}$, the level significantly affects the curvature and the slope, the former positively and the latter negatively. Finally, in $\mathrm{A}_{4}$, the three macro variables do not show significant cross interactions among them.

Taken together, important results emerge from the two models. First, setting the policy rate in Brazil takes into account financial factors and inflation, although the policy rate itself does not seem to have a significant effect either on inflation or on economic activity; ${ }^{48}$ second, changes in perceptions about Brazil risk, as measured by the risk perception variable, strongly influence the dynamics of the yield curve; third, although limited, bilateral feedback seems to be stronger from the macroeconomic variables to the yield curve than in the other direction; and fourth, macroeconomic variables exhibit a higher degree of persistence than yield curve variables. However, a more thorough analysis of the relation between yield movements and shocks in macro variables, and vice versa, would take into account the results from the impulse responses implied by the estimated VAR.

\footnotetext{
${ }^{47}$ The effect on next period's curvature could be interpreted as the result of the strong positive effect that changes in risk aversion have on the short and long end of the curve.

${ }^{48}$ There are other monetary policy instruments, like reserve requirements, that were actively managed by the central bank during the period.
} 


\begin{tabular}{|c|c|c|c|c|c|c|}
\hline & Level(-1) & Slope(-1) & Curvature(-1) & $\operatorname{INF}(-1)$ & $\mathrm{EA}(-1)$ & $\mathrm{RA}(-1)$ \\
\hline \multirow[t]{3}{*}{ Level } & 0.33 & 0.09 & -0.10 & 0.07 & 0.47 & 1.18 \\
\hline & (0.14507) & (0.16070) & $(0.08263)$ & (0.13560) & $(0.17465)$ & $(0.39352)$ \\
\hline & [2.29951] & [0.57219] & {$[-1.26578]$} & [0.49544] & [2.68807] & [2.99589] \\
\hline \multirow[t]{3}{*}{ Slope } & -0.63 & 0.99 & -0.17 & 0.01 & 0.40 & 1.11 \\
\hline & $(0.15776)$ & (0.17534) & (0.08918) & $(0.14643)$ & $(0.19280)$ & $(0.42813)$ \\
\hline & {$[-3.97251]$} & [5.63799] & [-1.90883] & [0.09193] & [2.07483] & [2.58837] \\
\hline \multirow[t]{3}{*}{ Curvature } & 0.54 & -0.38 & 0.75 & 0.56 & -0.21 & -2.13 \\
\hline & (0.18198) & $(0.20030)$ & $(0.10420)$ & (0.17669) & $(0.23337)$ & $(0.47317)$ \\
\hline & [2.94372] & {$[-1.88152]$} & [7.22345] & [3.19644] & {$[-0.88098]$} & {$[-4.50611]$} \\
\hline \multirow[t]{3}{*}{ INF } & -0.08 & 0.06 & -0.03 & 0.87 & 0.25 & 0.32 \\
\hline & $(0.10988)$ & $(0.12592)$ & $(0.06421)$ & $(0.10447)$ & $(0.14489)$ & $(0.28343)$ \\
\hline & {$[-0.71232]$} & [0.47571] & {$[-0.43603]$} & [8.32622] & [1.71240] & [1.13081] \\
\hline \multirow[t]{3}{*}{ EA } & -0.04 & -0.02 & -0.04 & 0.06 & 0.88 & -0.09 \\
\hline & $(0.07615)$ & $(0.08485)$ & $(0.04381)$ & $(0.06811)$ & $(0.09793)$ & $(0.19710)$ \\
\hline & {$[-0.57685]$} & {$[-0.20840]$} & {$[-0.99005]$} & [0.89773] & [8.96334] & {$[-0.47377]$} \\
\hline \multirow[t]{3}{*}{ RA } & 0.00 & 0.02 & 0.04 & -0.02 & 0.00 & 1.01 \\
\hline & $(0.04479)$ & $(0.04948)$ & $(0.02402)$ & $(0.03665)$ & $(0.05293)$ & $(0.11161)$ \\
\hline & {$[-0.03814]$} & [0.44435] & [1.46499] & {$[-0.41255]$} & {$[-0.08402]$} & [9.00545] \\
\hline
\end{tabular}

Source: Authors' estimates.

Results from the impulse response functions of both yield-macro models reveal complex and subtle dynamic interactions between macroeconomic variables and yield curve factors. Figures 6 and 7 display the impulse response functions of the complete yield-macro system for both, Model I and Model II, respectively. ${ }^{49}$ Four groups of impulse responses are considered: (i) responses of the macroeconomic variables to macroeconomic shocks; (ii) responses of the macroeconomic variables to yield curve shocks; (iii) responses of the yield curve to macroeconomic shocks; and (iv) responses of the yield curve to yield curve shocks. The analysis of the impulse responses for both yield-macro models will be undertaken separately in the next two subsections.

\footnotetext{
${ }^{49}$ Producing impulse responses from the VAR model requires assuming a particular ordering of the variables. The order of the variables used in this paper is similar to that followed by Diebold, Rudebusch and Aroba (2006). The term structure factors enter prior to the macroeconomic variables since they are dated at the beginning of the period. The results obtained are robust to different ordering of the macroeconomic variables.
} 


\section{Model I}

- Responses of macroeconomic variables to macroeconomic shocks. These are, in general, similar to those obtained in standard small macro models. ${ }^{50}$ The macroeconomic variables show significant persistence. ${ }^{51}$ In general, apart from the diagonal effects showing persistence, the only significant effect in this block of impulse responses is the positive response of the policy rate to a shock to inflation, which is consistent with the estimates results from the VAR regarding the factors determining the policy rate and the relative ineffectiveness of the policy rate on inflation and economic activity.

- Responses of macroeconomic variables to yield curve shocks. In general, the macroeconomic variables exhibit unimportant, and mostly insignificant, responses to shocks to the yield curve factor. The only significant effects are associated with the policy rate, which, for a very short period, responds negatively to a shock to the slope and positively to a shock to the curvature. ${ }^{52}$

- Responses of the yield curve to macroeconomic shocks. In general, shocks to macroeconomic variables do have little, and mostly insignificant, influence on the yield factors, with the only significant result being the positive effect of a shock to the level on inflation, reaffirming the close association between expected inflation and the level factor.

\footnotetext{
${ }^{50}$ See Diebold, Rudebusch and Aroba (2006) and the papers cited within.

${ }^{51}$ The least persistent is economic activity for which the effect of the shock disappears after 12 months.

${ }^{52}$ In view of the results from the previous bullet, the policy rate appears to exhibit significant persistence, and responds significantly, and with the appropriate signs, to shocks to inflation, the slope and the curvature. In fact, during the period of analysis, there were 64 meetings of the Brazilian Central Bank. Using survey data collected by the central bank on the day of the decision as a proxy for market expectations, we see that in 49 meetings (76.5 percent), the market anticipated the Central Bank’s decision. Furthermore, in the cases for which the movements were not anticipated, the error margin was very small (about 25 basis points compared to levels around 15 percent).
} 


\section{Figure 5. Model I-Impulse-Response Functions}

Response of LEVEL to LEVEL

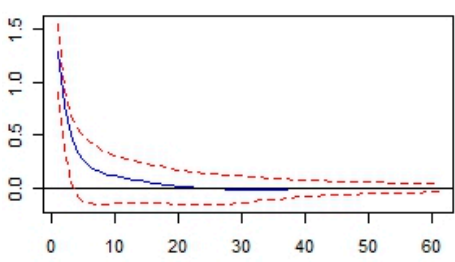

Response of SLOPE to LEVEL

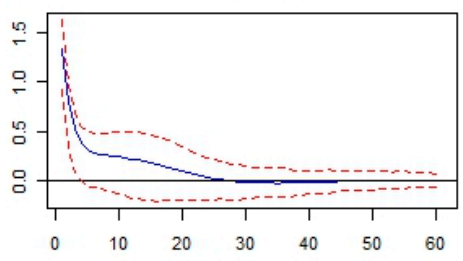

Response of CURVATURE to LEVEL

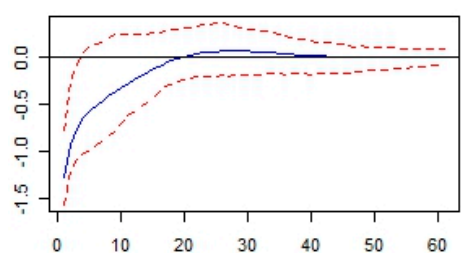

Response of INF to LEVEL

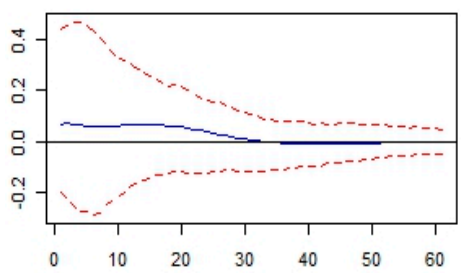

Response of EA to LEVEL

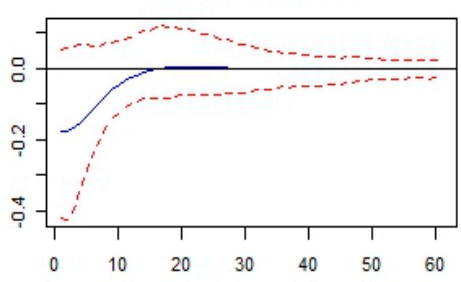

Response of TR to LEVEL

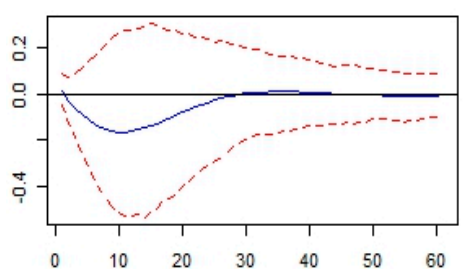

Source: Authors' estimates
Response of LEVEL to SLOPE

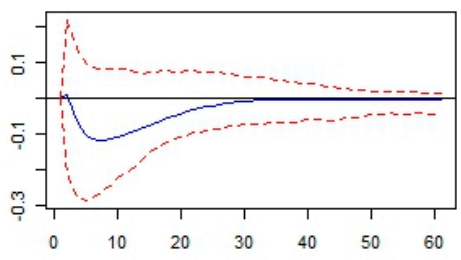

Response of SLOPE to SLOPE

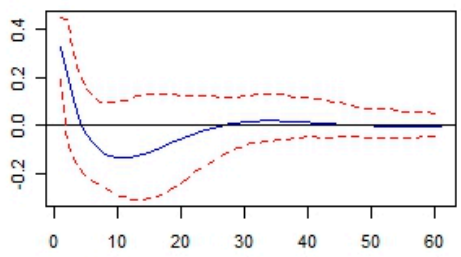

Response of CURVATURE to SLOPE

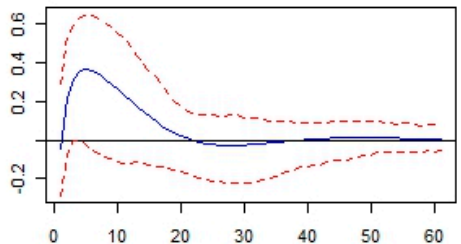

Response of INF to SLOPE

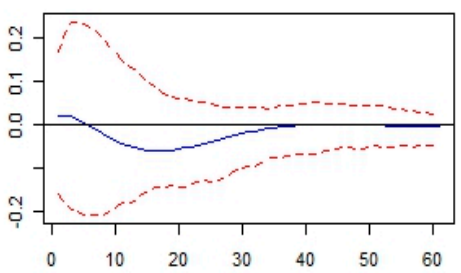

Response of EA to SLOPE

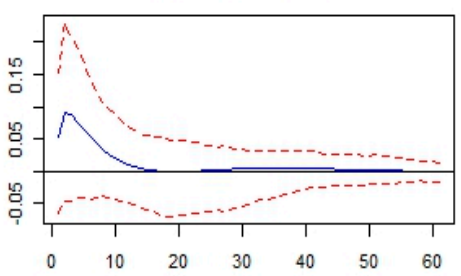

Response of TR to SLOPE

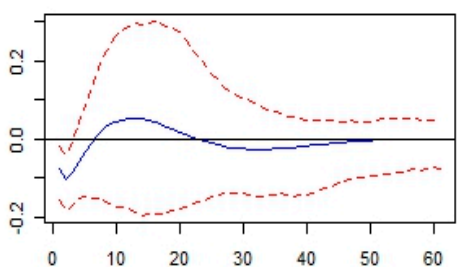

Response of LEVEL to CURVATURE

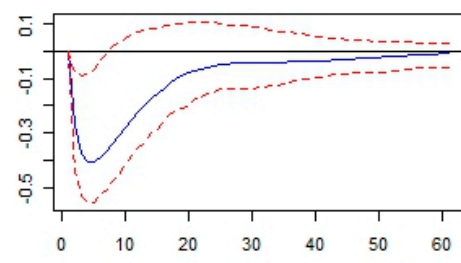

Response of SLOPE to CURVATURE

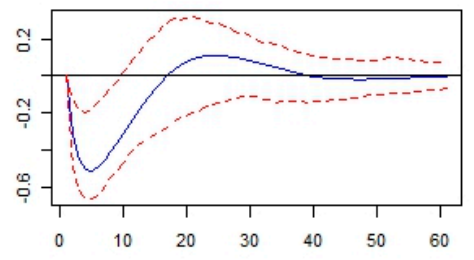

Response of CURVATURE to CURVATURE

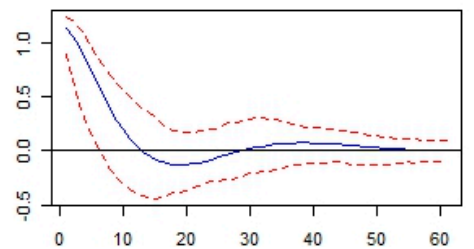

Response of INF to CURVATURE

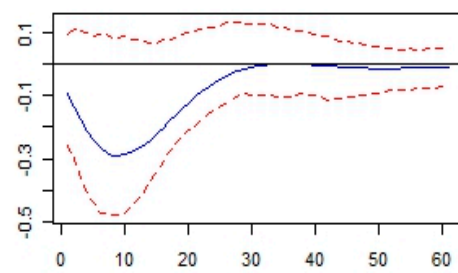

Response of EA to CURVATURE

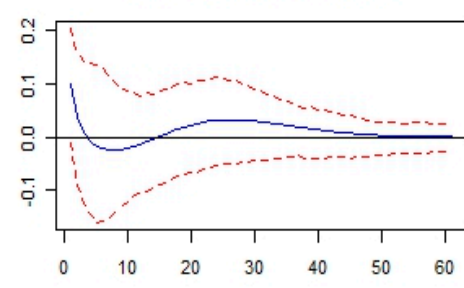

Response of TR to CURVATURE

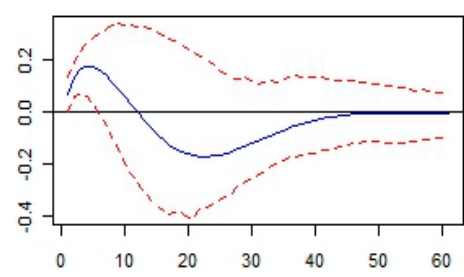


Figure 5. Model I-Impulse-Response Functions (concluded)
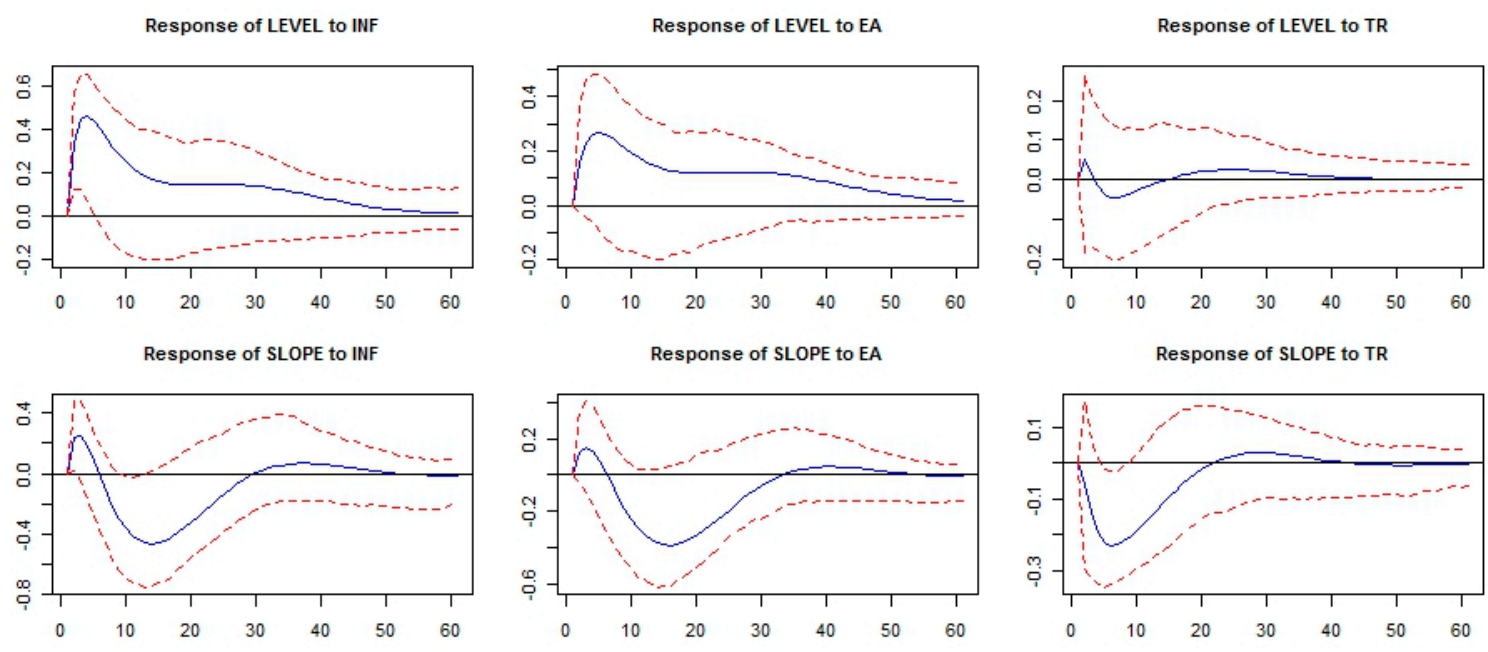

Response of SLOPE to EA
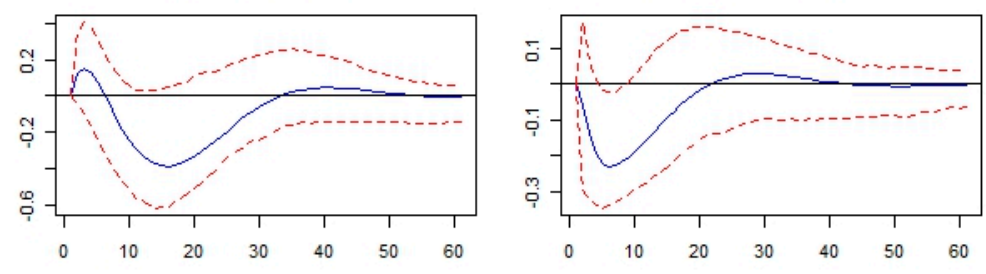

Response of CURVATURE to INF

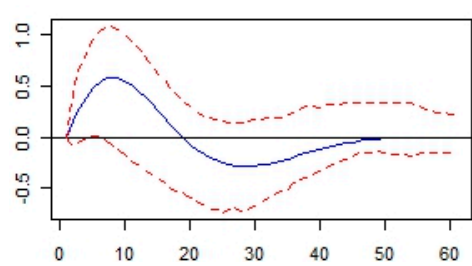

Response of CURVATURE to EA

Response of CURVATURE to TR
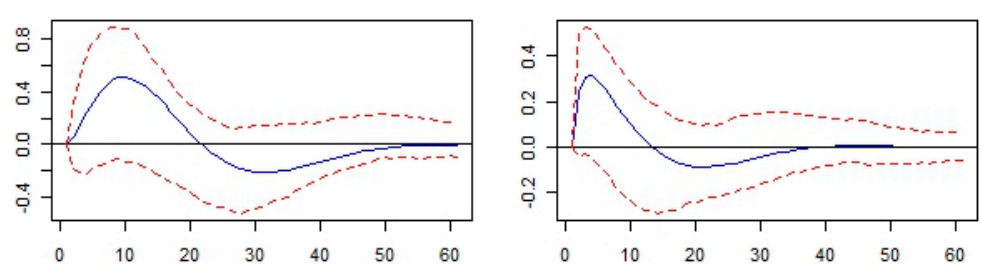

Response of INF to INF
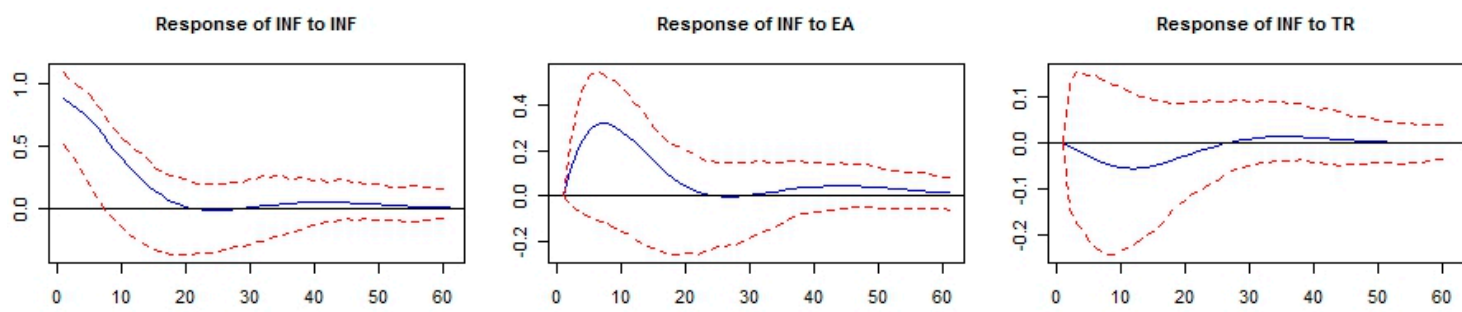

Response of EA to INF

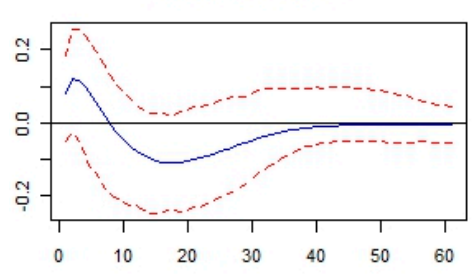

Response of EA to EA

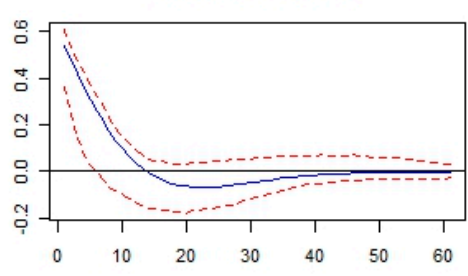

Response of EA to TR

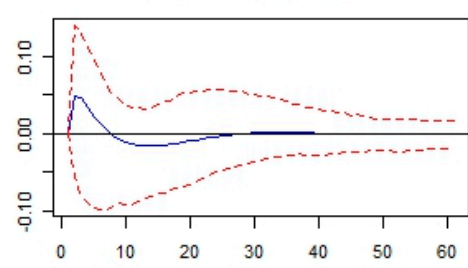

Response of TR to INF
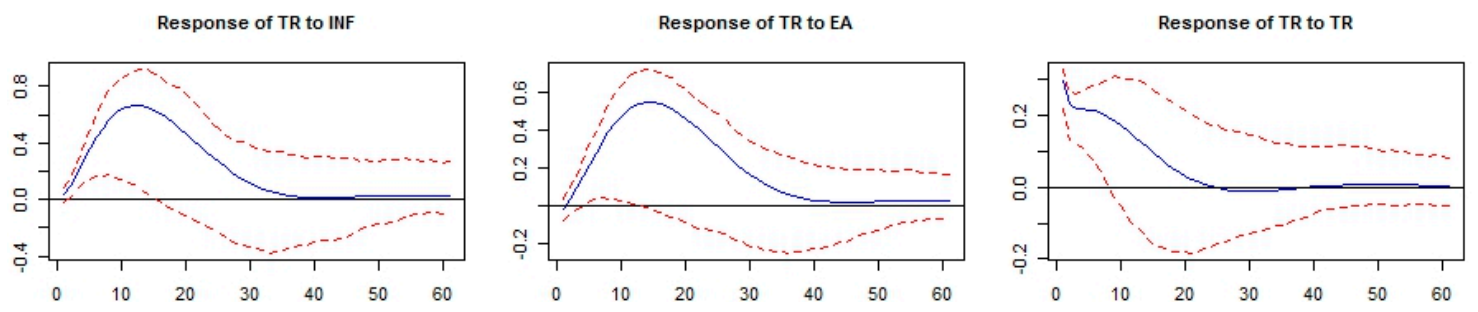

Source: Authors' estimates. 
- Responses of the yield curve to yield curve shocks. Different from the previous cases, shocks to yield curve factors appear to have significant influence on their own dynamics. Specifically, the three yield curve factors, significantly, display small persistence. Also, the level and the slope respond negatively to a shock to the curvature, while shocks to the level produce a positive response in the slope and a negative one in the curvature. In this respect, interpreting a shock to the level factor, as higher inflation expectations, the increase the slope, which is associated with a lowering of the short end of the curve relative to the long end, and a loosening of monetary policy. Finally, a surprise increase in the slope factor reduces the level factor, suggesting a shift in the total curve downwards, but with a relatively stronger decline in the short end of the curve.

\section{Model II}

- Responses of macroeconomic variables to macroeconomic shocks. As in Model I, the macroeconomic variables show persistence, although, in this case, particularly strong for the risk aversion variable. Similarly, the interactions between inflation and economic activity follow those obtained for Model I. For the case of risk perception, effects of an increase in this variable on inflation and economic activity, with their direction pointing to a reduction in inflation and an increase in economic activity. ${ }^{53}$ In the same way, shocks to inflation and economic activity have a negligible and insignificant effect on risk perception, with inflation affecting it negatively and economic activity positively, at least for a short period of time. ${ }^{54}$

- Responses of the macroeconomic variables to yield curve shocks. As in Model I, the macroeconomic variables exhibit unimportant, and mostly insignificant, responses to yield curve shocks. The only statistically significant, although brief, effect comes from the positive effect of a shock to the curvature on economic activity.

- Responses of the yield curve to macroeconomic shocks. In general, most shocks to inflation and economic activity have statistically insignificant and small effects on the yield curve factors. The new feature here is the statistically significant and temporary effects that shocks to risk perception have on the three yield factors. However, the results, for the period of analysis, pointing to a decrease in the level and the slope as a result of an increase to risk perception are difficult to rationalize. ${ }^{55}$ In addition, an increase to risk perception increases the curvature, indicating relatively higher yields in the mid section of the curve relative to the short and long ends.

\footnotetext{
${ }^{53}$ While the direction of the effect on economic activity is difficult to rationalize, the effect on inflation, in principle, could be associated to the downward effect that an increase in risk aversion may have on aggregate spending.

${ }^{54} \mathrm{As}$ in the case of shocks to risk aversion, the temporary positive effect of economic activity on risk aversion is difficult to rationalize, while the shock to inflation should have an adverse effect on risk aversion.

${ }^{55}$ One possible way of explaining the decrease in the slope is by assuming that this reduction comes from a relatively larger increase in the long end of the curve relative to the increase in the short end of the curve.
} 
- Responses of the yield curve to yield curve shocks. In general, the features of the responses of yield factors to their own shocks are basically the same as those in Model I. However, the persistence of shocks to the curvature and the level decline, while the persistence of shocks to the slope increases.

\section{Figure 6. Model II-Impulse-Response Functions}
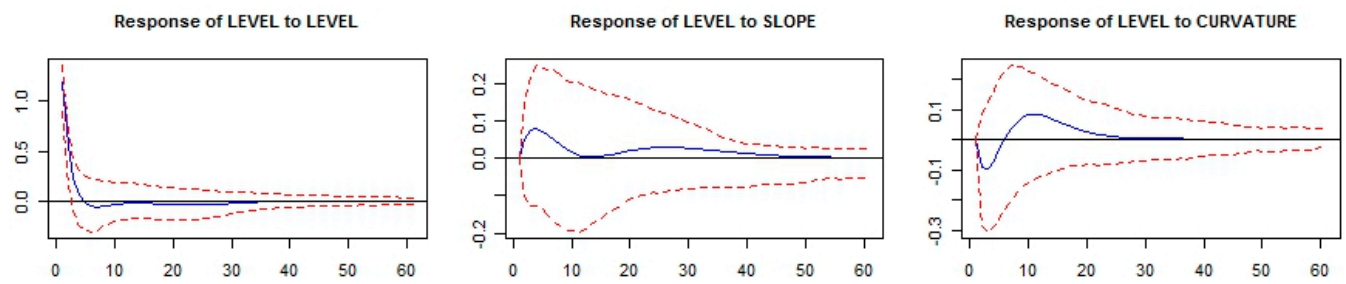

Response of SLOPE to LEVEL

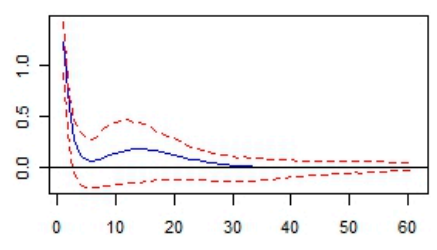

Response of SLOPE to SLOPE

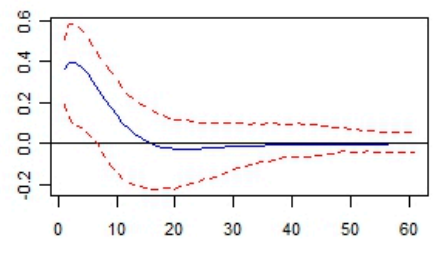

Response of SLOPE to CURVATURE

Response of CURVATURE to LEVEL

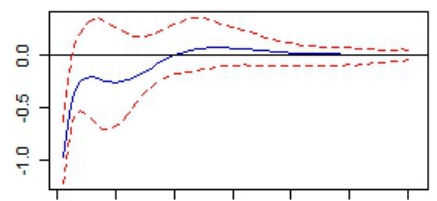

Response of CURVATURE to SLOPE
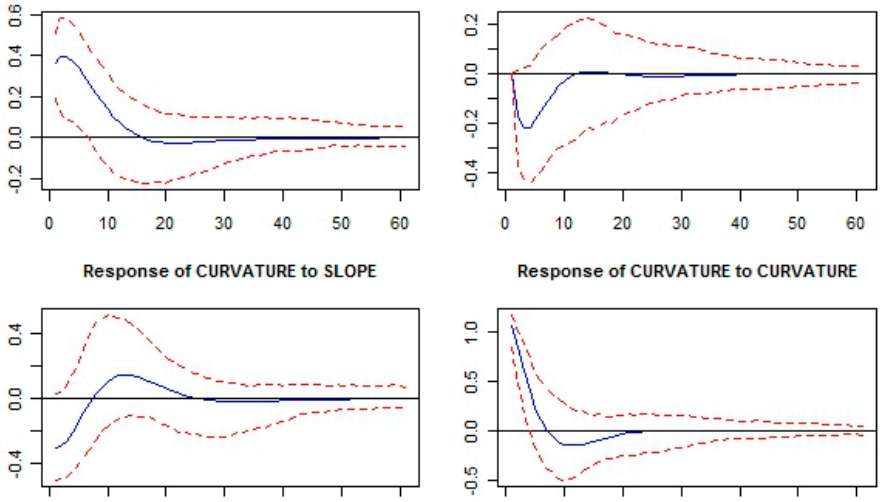

Response of INF to LEVEL
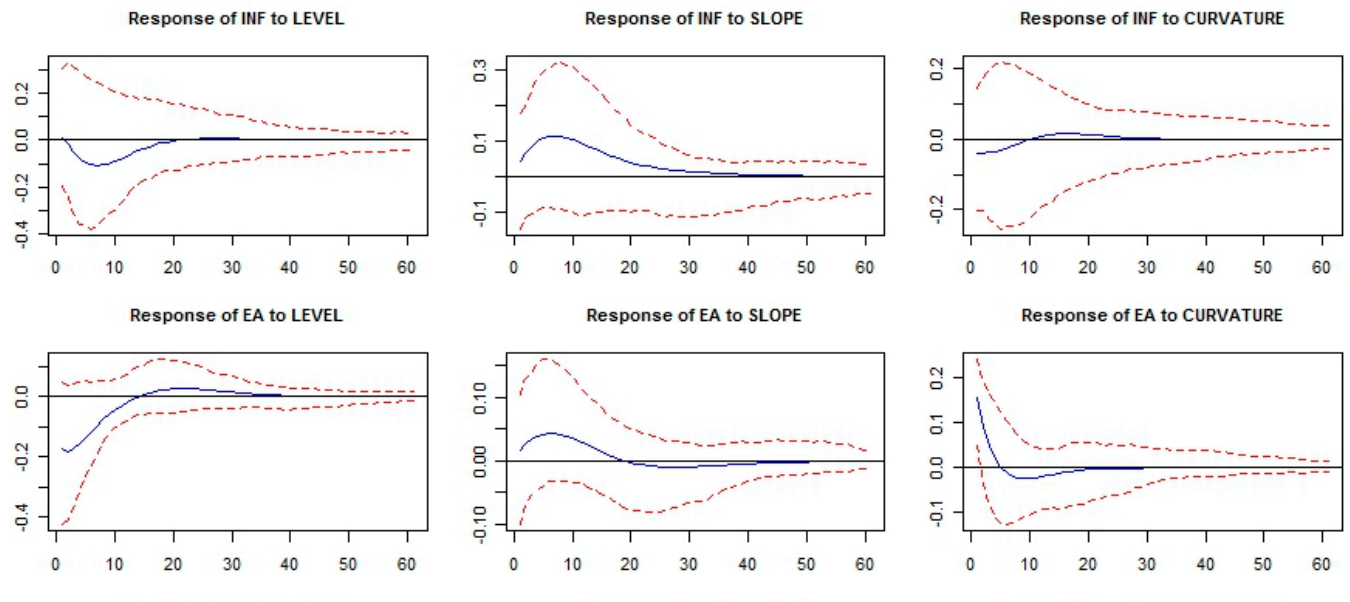

Response of RA to LEVEL
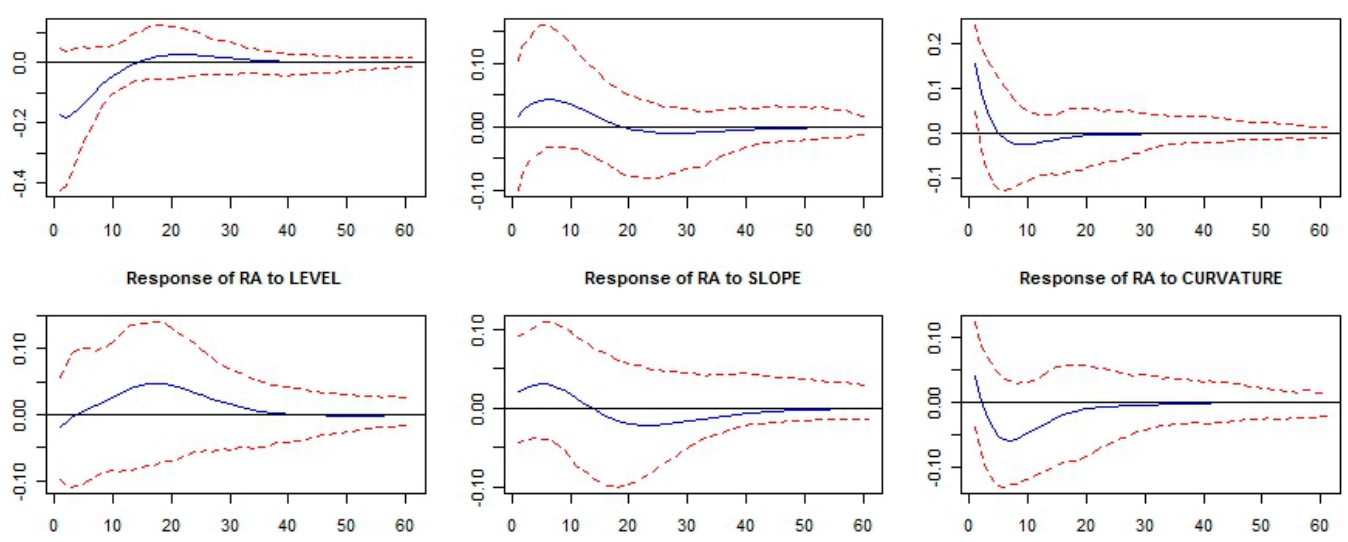

Response of RA to CURVATURE

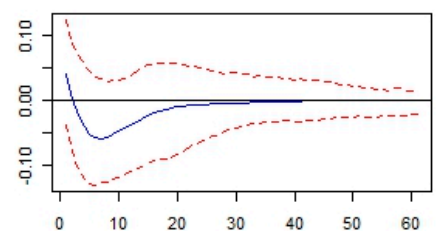

Source: Authors' estimates. 
Figure 6. Model II-Impulse-Response Functions (concluded)
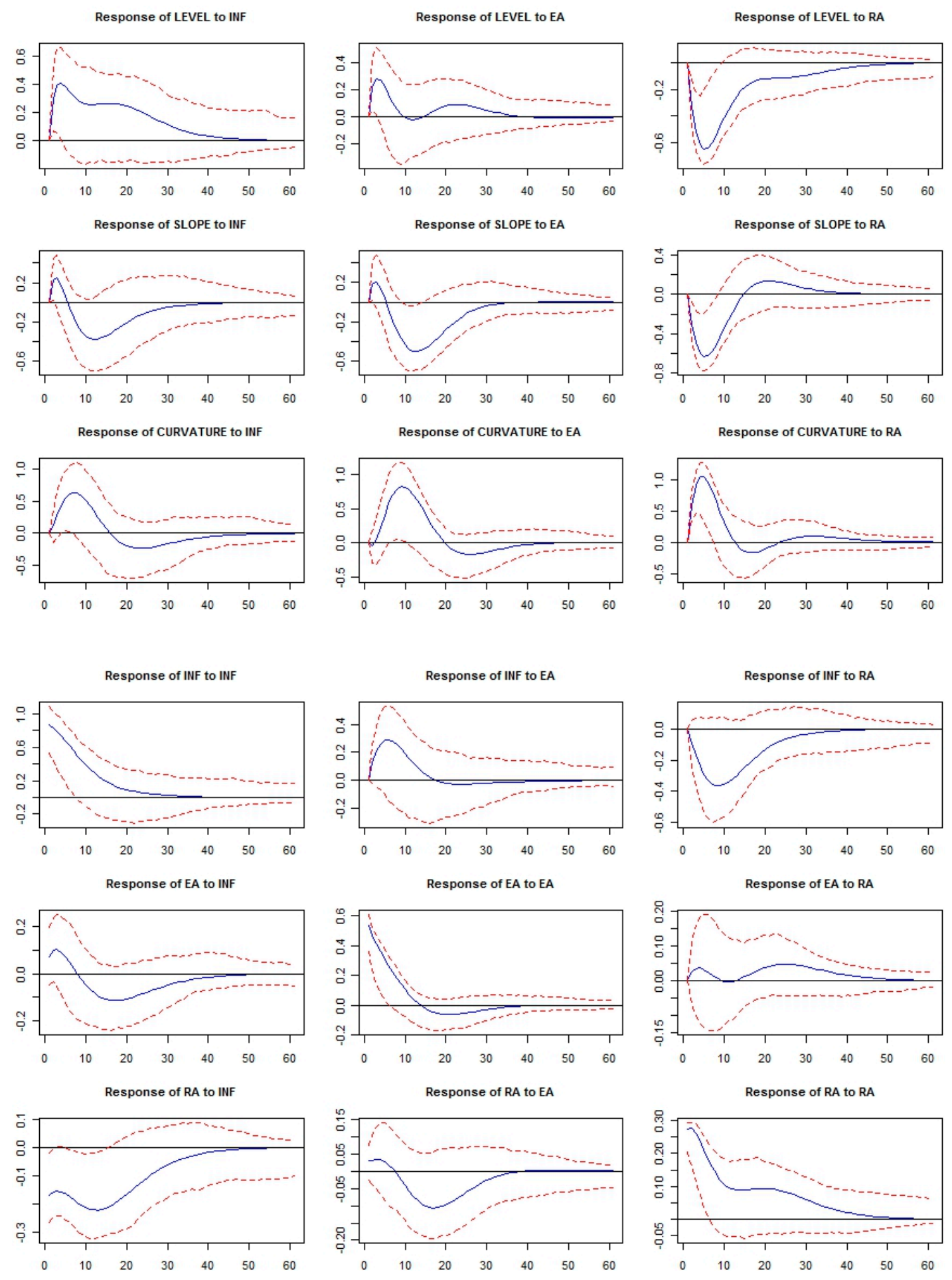

Source: Authors' estimates. 


\section{Conclusions}

\section{Several conclusions can be drawn from the discussion above:}

- Using estimates of the zero-coupon bond yields for Brazilian treasury bonds during the period 2004:1-2010-10, we were able to characterize the average Brazilian yield curve and its dynamics in terms of the statistical properties of the average yields for the available maturities, and in terms of the properties of its three key empirical factors, level, slope and curvature. Some significant findings include the substantial variation in these factors, as well as the high average level and small average slope during the period. We summarized these findings in a list of key empirical features of the Brazilian yield curve for the period, which provide a set of stylized facts that we aim to explain.

- We estimated a three-factor Nelson-Siegel model for the Brazilian yield curve. It fitted the yield data well and reproduced the stylized facts of the Brazilian yield curve for the period of analysis in terms of the statistical properties of the estimated factors. We then proceeded to expand the model to include a set of macroeconomic variables, which provided a way to explain the yields' dynamic interactions with key macroeconomic variables in the context of a VAR of order one. More precisely, we estimated two yield-macro models which, although provided a good fit to the yield data, faced severe estimation constraints derived from the limited availability of data on yields. We addressed this problem by using additional statistical techniques to reduce the uncertainty in the estimates caused by the small sample of yields, and were able to estimate the two VARs more confidently and to analyze the impulse responses derived from them.

- The first yield-macro model (Model I) contained six factors, the three yield factors plus three macro factors, the first principal components of variables measuring inflation and economic activity, respectively, and the policy rate; while the second model (Model II) included the first principal component from variables measuring risk aversion in place of the policy rate. From these two models it was possible to conclude that for the period of analysis: (i) the macrovariables exhibited higher persistence than the yield factors; (ii) the macrovariables exhibit unimportant, and mostly insignificant, responses to yield curve shocks; (iii) changes in perceptions about Brazil risk, as measured by a risk aversion indicator, strongly influence the dynamics of the yield curve; (iv) the setting of the policy rate in Brazil took into account financial factors and inflation, and (v) the policy rate itself does not seem to have a significant effect either on inflation or on economic activity.

- One key result from the analysis is then that there appears to be limited bilateral feedback between the yield curve and macroeconomic variables, which is slightly stronger from the macroeconomic variables to the yield curve. 


\section{REFERENCES}

Almeida, C. (2004). Time-varying Risk Premia in Emerging Markets: Explanation by a Multi-Factor Affine Term Structure, International Journal of Theoretical and Applied Finance 7.

Almeida, C., R. Gomes, A. Leite and J. Vicente (2007). Does Curvature Enhance Forecasting?, EPGE Working Paper, Getulio Vargas Foundation.

BIS (2005), Zero-Coupon Yield Curves: Technical Documentation, Bank for International Settlements, Basle.

Bjork, T. and B. Christensen (1999). Interest Rate Dynamics and Consistent Forward Rate Curves, Mathematical Finance, 130, 323-348.

Brazilian National Treasury (2009), “Public Debt: The Brazilian Experience”. National Treasury of Brazil and The World Bank.

Brito, R., A. Duarte and O. Guillen (2003). O Prêmio pela Maturidade na Estrutura a Termo das Taxas de Juros Brasileiras, Working Paper Series 72, Central Bank of Brazil.

Cabral et al. (2008), A Benchmark for Public Debt: The Brazilian Case. National Treasury of Brazil, Public Debt Strategic Planning Department, Brasília.

Cabral, R., W. Baghdassarian and A. Silva (2006). Scope and Fundamental Challenges of Public Debt Risk Management - The Brazilian DMO Experience.

Diebold, F. X. and C. Li (2006). Forecasting the term structure of government bond yields, Journal of Econometrics, 130, 337-364.

Diebold, F. X., M. Piazzesi, and G. D. Rudebusch (2005). Modeling bond yields in finance and macroeconomics, American Economic Review, 95, 415-420.

Diebold, F. X., G. D. Rudebusch, and B. Auroba (2006). The Macroeconomy and the Yield Curve: a Dynamic Latent Factor Approach, Journal of Econometrics, 131, 309-338.

Gasha, G., Y. He, C. Medeiros, M. Rodriguez, J. Salvati, and J. Yi, 2010, “On the Estimation of Term Structure Models and An Application to the United States,” Working Paper 10/258, November (Washington DC: International Monetary Fund).

Lima, A. and J. Issler (2003). A Hipótese das Expectativas na Estrutura a Termo de Juros no Brasil: Uma Aplicação de Modelos de Valor Presente, Revista Brasileira de Economia. 
Litterman, R. and J. Scheinkman (1991), Common Factors Affecting Bond Returns, Journal of Fixed Income, 54-61.

Matsumura, M. and A. Moreira (2005). Can Macroeconomic Variables Account for the Term Structure of Sovereign Spreads?, Studying the Brazilian Case Discussion, Paper 1106, Institute of Applied Economic Research.

Matsumura, M. and A. Moreira (2006). Macro Factors and the Brazilian Yield Curves with no-Arbitrage Models, Discussion Paper 1210, Institute of Applied Economic Research.

Matsumura, M.S., A.R. Moreira and J.V. Vicente (2010). Forecasting the Yield Curve with Linear Factor Models, Working Paper Series 223, Central Bank of Brazil.

Monteiro (2003). Estimação da Curva de Juros a Vista: Microestrutura dos Contratos e Restrição do Formato da Curva a Termo.

Nelson, C. R. and A. F. Siegel (1987), Parsimonious Modeling of Yield Curves, Journal of Financial and Quantitative Analysis, 60, 473-489.

Rezende, R. B. and M. S. Ferreira (2008), Modeling and Forecasting the Brazilian Term Structure of Interest rates br an Extended Nelson-Siegel class of Models: A Quantile Autoregression approach. Center for Development and Regional Planning, Belo Horizonte, Brazil.

Ribeiro, P.F and P.L. Pereira (2010), Economic Cycles and Term Structure: Application to Brazil, Getulio Vargas Foundation, São Paulo.

Rudebusch G. and L.E.O. Svensson (2003), Policy rules for inflation targeting. In: Taylor, J.B. (Ed.), Monetary Policy Rules. University of Chicago Press, Chicago, pp. 203-246.

Rudebusch G. and T. Wu (2008), A Macro-Finance Model of the Term Structure, Monetary Policy and the Economy. The Economic Journal, 118 (July), pp. 906-926.

Siegel A. F. and C. R. Nelson (1988), Long-Term Behavior of Yield Curves, Journal of Business, 23, 105-110.

Silveira, M. (2005), Modelo Fatorial Linear Macroeconômico de Estrutura a Termo da Taxa de Juros: Aplicação Para a Economia Brasileira. Discussion Paper Institute of Applied Economic Research 1097. 
Silveira, G and O. Bessada (2003), Análise de Componentes Principais de Dados Funcionais: Uma Aplicação às Estruturas a Termo de Taxas de Juros. Working Paper Series 73, Central Bank of Brazil.

Stotter D. and K. Kentwall (1991), Bootstrapping State-Space Models: Gaussian Maximum Likelihood Estimation of the Kalman Filter, Journal of the American statistical Association, Vol. 86, 416, 1024-1033.

Tabak, B.M. and S.C. Andrade (2001), Testing the Expectations Hypothesis in the Brazilian Term Structure of Interest Rates. Working Papers Series 30, Central Bank of Brazil.

Valli, M. and G. Varga (2002), Movimentos da Estrutura a Termo da Taxa de Juros Brasileira. In: Bonomo, M. (Ed.). Rio de Janeiro, FGV.

Vicente, J. and B. Tabak (2007), Forecasting Bond Yields in the Brazilian Fixed Income Market. International Journal of Forecasting. 


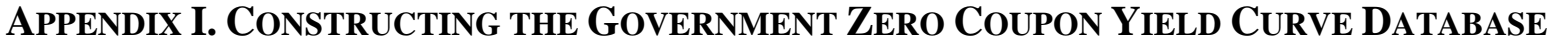 FOR BRAZIL}

The yield curve data used in this study was obtained from the Brazilian Association of Financial and Capital Market Institutions (ANBIMA). It was created in October, 2009 by joining the Brazilian Association of Financial Market Institutions (ANDIMA) and the Brazilian Association of Investment Banks (ANBID). One of its activities is to provide financial prices that allow financial institutions to mark-to-market their securities. Before October, 2009, the prices for the Government Bonds were provided by ANDIMA.

ANBIMA supplies prices for the government bonds based on fair prices provided by a sample of financial and capital market institutions which participate in the Brazilian bond market. The sample includes ANBIMA's price-makers (the main dealers) - open-market dealers, and other relevant institutions that participate in the in the market for government bonds.

In practice, although trading volume is low and activity is dispersed among the different instruments (according to time to maturity), the information received by ANBIMA and the methodology applied is sufficient to obtain the average yield to price the majority of bonds. Some prices used are synthetic, in that they are not based on actual trading, but on quotes from a sample of dealers. Ex-post comparisons with effective yields observed in trading indicate high correlation between synthetic and actual prices.

\section{Computing Zero Coupon Yields}

There are two fixed rate instruments issued by the National Treasury; (i) the National Treasury bills, denoted LTN, which are zero-coupon bonds, with time to maturity of up to about 2 years, and (ii) the National Treasury Notes - Series F, named NTN-F, which are long-term fixed rate coupon bonds, with time to maturity of up to about 10 years. ANBIMA provides daily prices and, therefore, yields to maturity (YTM) for both instruments. To compute a time series of zero coupon yields for specific constant maturities, two steps are necessary. First, the zero coupon yields are recovered from the LTN and NTNF data. This is achieved via bootstrapping; a method that allows for the recovery of zero yields from coupon-bearing bonds. Second, constant maturity yields are obtained by interpolation.

The bootstrapping procedure is not necessary for maturities for which zero coupon bonds are available. For longer maturities, the following describes the bootstrapping procedure that is applied sequentially from the shortest to the longest maturity reference NTN-F:

- Calculate the price $\left(P^{y t m}\right)$ of each reference bond of based on its YTM, given that the bond has periodic coupon payments $\mathrm{C}$, face value $\mathrm{F}$ and $\mathrm{n}$ periods to maturity. 


$$
P^{y t m}=\sum_{\tau=1}^{n} \frac{c}{(1+Y T M)^{\tau}}+\frac{F}{(1+Y T M)^{n}}
$$

- Calculate the price $\left(P^{z}\right)$ based on the discount factors available from zero coupon bonds or previous steps of the bootstrapping algorithm.

$$
P^{z}=\sum_{i=1}^{n} \frac{c}{\left(1+r\left(0, \tau_{i}\right)\right)^{\tau_{i}}}+\frac{F}{\left(1+r\left(0, \tau_{n}\right)\right)^{\tau_{n}}}
$$

In the expression (2), there are $\mathrm{n}$ cash-flows dates, but zero coupon yields are known for only $\mathrm{m}(1 \leq \mathrm{m}<\mathrm{n})$ maturities. ${ }^{56}$ Rewriting (2) yields

$$
P^{z}=\sum_{i=1}^{m} \frac{c}{\left(1+r\left(0, \tau_{i}\right)\right)^{\tau_{i}}}+\sum_{j=m+1}^{n} \frac{c}{\left(1+r\left(0, \tau_{j}\right)\right)^{\tau_{j}}}+\frac{F}{\left(1+r\left(0, \tau_{n}\right)\right)^{\tau_{n}}}
$$

where the following relations are valid.

$$
\begin{aligned}
& r\left(0, \tau_{n}\right)=\left[\left(1+r\left(0, \tau_{m}\right)\right)^{\tau_{m}}\left(1+r\left(\tau_{m}, \tau_{n}\right)\right)^{\left(\tau_{n}-\tau_{m}\right)}\right]^{1 / \tau_{n}}-1 \\
& r\left(0, \tau_{j}\right)=\left[\left(1+r\left(0, \tau_{m}\right)\right)^{\tau_{m}}\left(1+r\left(\tau_{m}, \tau_{n}\right)\right)^{\left(\tau_{j}-\tau_{m}\right)}\right]^{1 / \tau_{j}}-1
\end{aligned}
$$

To recover $r\left(\tau_{i-1}, \tau_{i}\right)$, and consequently $r\left(0, \tau_{i}\right)$, we can equate $P^{y t m}$ to $P^{z}$ via the law of one price. Constant maturity yields are obtained by interpolation.

\footnotetext{
${ }^{56} \mathrm{At} \mathrm{least}$ one zero coupon yield is needed before beginning the bootstrapping procedure (the LTN provide this information).
} 